NBER WORKING PAPER SERIES

\title{
LUMPY DURABLE CONSUMPTION DEMAND AND THE LIMITED AMMUNITION OF MONETARY POLICY
}

\author{
Alisdair McKay \\ Johannes F. Wieland \\ Working Paper 26175 \\ http://www.nber.org/papers/w26175 \\ NATIONAL BUREAU OF ECONOMIC RESEARCH \\ 1050 Massachusetts Avenue \\ Cambridge, MA 02138 \\ August 2019
}

We are grateful to Adrien Auclert, Robert Barsky, David Berger, Jeff Campbell, Adam Guren, Christopher House, Rohan Kekre, Emi Nakamura, Valerie Ramey, Jon Steinsson, Stephen Terry, Joe Vavra, Venky Venkateswaran, Tom Winberry, Christian Wolf, and seminar participants at Boston University, University of Michigan, the Federal Reserve Banks of Minneapolis and St. Louis, the 2019 ASSA meetings, U.C. Berkeley, Chicago Booth, SED 2019, and the 2019 NBER Summer Institute. Charles Fries provided excellent research assistance. Wieland is grateful to the Federal Reserve Bank of Chicago for its hospitality while completing much of this paper. The views expressed here are those of the authors and do not necessarily reflect the position of the Federal Reserve Bank of Minneapolis, the Federal Reserve Bank of Chicago, the Federal Reserve System, or the National Bureau of Economic Research.

NBER working papers are circulated for discussion and comment purposes. They have not been peer-reviewed or been subject to the review by the NBER Board of Directors that accompanies official NBER publications.

(C) 2019 by Alisdair McKay and Johannes F. Wieland. All rights reserved. Short sections of text, not to exceed two paragraphs, may be quoted without explicit permission provided that full credit, including $\odot$ notice, is given to the source. 
Lumpy Durable Consumption Demand and the Limited Ammunition of Monetary Policy Alisdair McKay and Johannes F. Wieland

NBER Working Paper No. 26175

August 2019

JEL No. E21,E43,E52

\begin{abstract}
In a fixed-cost model of durable consumption demand, we show that an important channel of monetary policy transmission is to prompt households to accelerate the timing of their adjustments. We highlight three ways in which the power of monetary policy is reduced relative to the standard New Keynesian model. First, there is an intertemporal trade-off in aggregate demand as encouraging households to adjust today leaves fewer households acquiring durables going forward. Second, households make a short-term decision-adjusting now rather than in the near future - so the short-term real interest rate is the opportunity cost of adjusting today. As a result, forward guidance is less effective at shifting aggregate demand than contemporaneous interest rate cuts. Third, monetary policy becomes less powerful in a recession. The literature has debated whether fixed-cost models generate state dependence in general equilibrium; we show that if one conditions on the magnitude of the recession, the model's state dependence is unaffected by general equilibrium attenuation.
\end{abstract}

\author{
Alisdair McKay \\ Federal Reserve Bank of Minneapolis \\ 90 Hennepin Avenue \\ Minneapolis, MN 55401 \\ and NBER \\ alisdair.mckay@gmail.com \\ Johannes F. Wieland \\ Department of Economics \\ University of California, San Diego \\ 9500 Gilman Drive \#0508 \\ La Jolla, CA 92093 \\ and NBER \\ jfwieland@ucsd.edu
}




\section{Introduction}

Expenditure on durable consumption goods is a particularly interest-rate-sensitive and volatile component of aggregate demand. At the micro-level these expenditures are infrequent and lumpy. Do the micro-foundations of durable goods demand affect the monetary transmission mechanism? We explore this question using a heterogeneous-agent New Keynesian model with fixed costs for durable adjustment.

Our work builds on a growing literature that models aggregate demand using rich microfoundations for household consumption that are disciplined by micro-data. ${ }^{1}$ Most of this literature focuses its attention on the determination of non-durable consumption and abstracts from consumer durables. Our interest in durable goods is motivated by the fact that they are more sensitive to monetary policy and in general more cyclical than non-durable consumption. For example, durable goods account for $61 \%$ of the response of total consumption to an identified monetary shock (see Section 3).

We start with a household decision problem with incomplete markets and fixed costs of adjusting durable holdings similar to the one developed by Berger and Vavra (2015). Since our focus is on monetary policy transmission, we benchmark the model against the empirical sensitivity of durable demand to interest rates using identified monetary policy shocks and quasi-experimental evidence. House (2014) has pointed out that standard fixed-cost models have very high interest elasticities of durable expenditure. We show that including two particular ingredients in the model are important to match the empirical evidence, without which the model-implied interest elasticity of durable demand is an order of magnitude larger than our empirical benchmarks. First, operating costs are a component of the user cost of durables that is not sensitive to interest rates. Second, matchquality shocks reduce the service flow from a household's existing durable stock and prompt an inframarginal adjustment. We use micro-data on durable adjustments to estimate the frequency of match-quality shocks.

We then embed this model of lumpy durable demand within a general equilibrium context that features nominal rigidities in the form of sticky wages. A key channel of monetary transmission is to accelerate the timing of adjustments of household durable stocks. We stress three implications

\footnotetext{
${ }^{1}$ See Guerrieri and Lorenzoni (2017), McKay and Reis (2016), Gornemann et al. (2016), McKay et al. (2016), Auclert (2019), Kaplan et al. (2018), Werning (2015) among others.
} 
of this mechanism for the effects monetary policy. First, a substantial part of the stimulative effect of low interest rates arises from intertemporally shifting demand from the future. After households have accelerated their adjustments, there are fewer households near the adjustment threshold and demand is weaker than it otherwise would have been. Second, the decision to adjust the durable stock has a short-term nature as marginal households are likely to adjust their durables soon in the absence of stimulus. The opportunity cost of accelerating the adjustment is the foregone interest over the time period that the adjustment is brought forward. As a result, short-term interest rates are especially relevant for the timing decision, whereas forward guidance is a much less powerful in shifting aggregate demand. Third, durable demand becomes less sensitive to stimulus if there are fewer households near the adjustment threshold. As a result, monetary policy loses power just when it is needed following shocks that reduce durable demand, which has been documented empirically by Tenreyro and Thwaites (2016).

The intertemporal shifting of demand implies that a central bank has scope to affect the ammunition available, or "policy space," in the future. This gives some credibility to the notion that a central bank facing an effective lower bound on nominal rates (ELB) may want to keep its powder dry if it is concerned about weaker demand in the future.

The implications of our model stand in contrast to standard models of the monetary transmission mechanism. As a point of reference, consider the linearized consumption Euler equation, which is at the heart of standard models of the monetary transmission mechanism (e.g. Woodford, 2003; Gali, 2008). Solving the Euler equation forward and using the national income identity yields

$$
y_{t}=-\frac{1}{\sigma} \mathbb{E}_{t} \sum_{s=0}^{\infty} r_{t+s}
$$

where $y_{t}$ is the log-deviation of output from its steady state value, $1 / \sigma$ is the intertemporal elasticity of substitution, and $r_{t}$ is the deviation of the real interest rate. From this equation, we can make three observations: (i) output is purely forward-looking and the history of interest rates is irrelevant. Because of this, future policy space is independent of current policy. (ii) Future interest rate reductions perfectly substitute for reductions in the contemporaneous interest rate. As a result, forward guidance is a powerful tool for managing demand at the ELB. (iii) The effect of an interest rate change on output is constant and unrelated to the state of the economy. These features of standard models are mirrored in the ways many central banks operate: low-for-longer policies (e.g. Reifschneider and Williams, 2000; Eggertsson and Woodford, 2003) are viewed as important 
unconventional monetary policy tools and managing policy space is not viewed as an important policy consideration.

We summarize the quantitative magnitude of our results by calculating how large an output gap the central bank can close today by committing to cut real interest rates 2.5 percentage points for four quarters. We use this as a measure of policy space. This calculation is motivated by the fact that current estimates of the nominal natural rate of interest in the U.S. are in the range of $2.5 \%^{2}$ and that a central bank might plausibly commit to a policy path for one year. If future interest rates are as effective in stimulating demand as current interest rates, the central bank has 6.2 percentage points of policy space. Given that forward guidance is less powerful in our model, policy space falls to $4.8 \%$. If the central bank has previously done four quarters of stimulus, policy space is reduced to $3.3 \%$. If on top of this, there is a recession that reduces durable expenditure by the amount observed in the Great Recession, policy space falls further to $2.0 \%$. In the recession scenario, policy space would have been $2.9 \%$ had the central bank not previously stimulated the economy. These results show that monetary policy has limited ammunition during recessions and that current stimulus can substantially reduce the central bank's ability to manage reductions in demand in the future.

Our findings can help resolve the forward guidance puzzle. Standard monetary models predict implausibly large output responses to forward guidance (Del Negro et al., 2015; Carlstrom et al., 2015). In response, one strand of literature has developed alternative models in which non-durable consumption is less forward looking (McKay et al., 2016; Werning, 2015; Farhi and Werning, 2017; Gabaix, 2016; Angeletos and Lian, 2018). We show that including durable goods makes aggregate demand less sensitive to promises of lower interest rates far in the future. Though non-durable expenditures are still quite forward looking in our model, the overall response of the economy to monetary stimulus is shaped by the patterns of durable expenditure.

This paper also relates to the literature on the aggregate implications of lumpiness in investment dynamics. The literature has debated how strongly general equilibrium forces attenuate the nonlinear dynamics generated by microeconomic lumpiness (e.g. Khan and Thomas, 2008; Bachmann et al., 2013). We show that the state-dependence of the power of monetary policy is essentially unaffected by general equilibrium movements of the real interest rate if one holds fixed the size

\footnotetext{
${ }^{2}$ See, for example, the Summary of Economic Projections of the Federal Reserve released in June 2019 in which the central tendency of Federal Funds Rate in the longer run is the range 2.5-3.0\%.
} 
of the recession. This is because the size of the recession is closely linked to the decline in the extensive margin, which acts as a sufficient statistic for state dependence in our model. This perspective differs from recent insights on the role of the interest elasticity of durable demand in the aggregation of heterogeneous firm models (House, 2014; Winberry, 2018; Koby and Wolf, 2018). The interest rate elasticity is a key determinant of the cyclicality of the extensive margin, and thereby the degree of state dependence for a given sized shock. We instead treat the size of the recession as an observable moment that we match, which pins down the extensive margin decline and the loss of monetary policy effectiveness.

Our framework builds on Berger and Vavra (2015), who document sizable state dependence of durable expenditures in a flexible price model. We show that durable goods are also important for the monetary transmission mechanism in other ways, specifically the reduced power of forward guidance and the intertemporal trade-off in aggregate demand. Moreover, we provide a novel perspective on the general equilibrium attenuation of state dependence.

We are not the first to emphasize the importance of durable goods for the monetary policy transmission mechanism. Our contribution to the existing literature is to show that movements in the extensive margin of durable demand have several important implications for the monetary transmission mechanism. In a representative agent framework, Barsky et al. (2007) show that monetary non-neutrality is primarily determined by nominal rigidities in the durable sector, and Barsky et al. (2016) show that this feature is important for optimal monetary policy. Sterk and Tenreyro (2018) build an OLG model, in which redistribution away from current generations due to inflationary monetary policy lowers real interest rates and creates a boom in durable spending. Kaplan et al. (2018) focus on the role of illiquid assets in raising the MPC and show this increases the importance of indirect effects in monetary transmission to non-durable consumption. Luetticke (2019) explores how monetary policy affects household demand for liquidity with consequences for aggregate investment in a model in which capital holdings adjust solely on the intensive margin.

Recent work has documented another form of state dependence in monetary policy stemming from fixed-rate mortgages (Berger et al., 2018; Eichenbaum et al., 2018). As interest rates fall, homeowners refinance to lower interest rate mortgages, thereby reducing their mortgage payments. This mechanism is stronger if there are more homeowners with existing high-rate mortgages, which is the case if interest rates have been high in the past. Our results are driven by a different state 
variable - the distribution of durable holdings relative to the adjustment thresholds.

The paper is organized as follows: Section 2 presents our model of demand for durable consumption goods; Section 3 discusses the interest elasticity of durable demand in the model and the data and the roles of match-quality shocks and operating costs in reducing this elasticity; Section 4 describes the general equilibrium model with sticky wages; Section 5 presents the main results on durable demand and the monetary policy transmission mechanism; Section 6 discusses the extent to which general equilibrium forces attenuate the aggregate implications of lumpy durable demand; Section 7 concludes.

\section{Model of Durable Demand}

We begin with the household's partial equilibrium decision problem, which forms the demand side of the model. A key step is to discipline the model's interest rate elasticity of durable demand. Later we will embed this demand block into a sticky-wage monetary model.

\subsection{Household's Problem}

Households consume non-durable goods, $c$, and a service flow from durable goods, $s$. Household $i \in[0,1]$ has preferences given by

$$
E_{0} \int_{t=0}^{\infty} e^{-\rho t} u\left(c_{i t}, s_{i t}\right) \mathrm{d} t
$$

The service flow from durables is generated from the household's stock of durable goods $d_{i t}$. For the most part we have $s_{i t}=d_{i t}$, but we will complicate this relationship below.

Households hold a portfolio of durables and liquid assets denoted $a_{i t}$. When a household with pre-existing portfolio $\left(a_{i t}, d_{i t}\right)$ adjusts its durable stock, it reshuffles its portfolio to $\left(a_{i t}^{\prime}, d_{i t}^{\prime}\right)$ subject to the payment of a fixed cost such that

$$
a_{i t}^{\prime}+p_{t} d_{i t}^{\prime}=a_{i t}+(1-f) p_{t} d_{i t}
$$

where $p_{t}$ is the relative price of durable goods in terms of non-durable goods, and $f p_{t} d_{i t}$ is a fixed cost proportional to the value of the durable stock. Liquid savings pay a safe real interest rate $r_{t}$. The household is able to borrow against the value of the durable stock up to a loan-to-value (LTV) 
$\operatorname{limit} \lambda$

$$
a_{i t} \geq-\lambda(1-f) p_{t} d_{i t}
$$

Borrowers pay real interest rate $r_{t}+r^{b}$, where $r^{b}$ is a time-invariant borrowing spread.

The stock of durables depreciates at rate $\delta$. Following Bachmann et al. (2013), a fraction $\chi$ of depreciation must be paid immediately in the form of maintenance expenditures. This maintenance reduces the drift rate of the durable stock so we have

$$
\dot{d}_{i t}=-(1-\chi) \delta d_{i t},
$$

where a dot over a variable indicates a time derivative. The household must also pay a flow cost of operating the durable stock equal to $\nu p_{t} d_{i t}$. Broadly speaking these operating costs reflect expenditures such as fuel, utilities, and taxes.

When a household does not adjust its durable stock, its liquid assets evolve according to

$$
\dot{a}_{i t}=r_{t} a_{i t}+r^{b} a_{i t} I_{\left\{a_{i t}<0\right\}}-c_{i t}+y_{i t}-(\chi \delta+\nu) p_{t} d_{i t} .
$$

Household income, $y_{i t}$, is given by

$$
y_{i t}=Y_{t} z_{i t}
$$

where $Y_{t}$ is aggregate income and $z_{i t}$ is the household's idiosyncrtic income share, which we later interpret as idiosyncratic labor productivity. $\ln z_{i t}$ follows the Ohrnstein-Uhlenbeck process

$$
\operatorname{dln} z_{i t}=\rho_{z} \ln z_{i t} \mathrm{~d} t+\sigma_{z} \mathrm{~d} \mathcal{W}_{i t}+\left(1-\rho_{z}\right) \ln \bar{z} \mathrm{~d} t
$$

where $\mathrm{d} \mathcal{W}_{i t}$ is a standard Brownian motion, $\rho_{z}<0$ controls the degree of mean reversion of the income process, $\sigma_{z}$ determines the variance of the income process, and $\bar{z}$ is a constant such that $\int z_{i t} \mathrm{~d} i=1$.

We allow for the possibility that households may occasionally adjust their durables because their existing durables are no longer a good match for them. These match-quality shocks are meant to capture unmodeled life events that leave the household wanting to adjust for reasons other than income fluctuations and depreciation. For example, a job offer in a distant city may prompt the household to move houses. Or a growing family may require a larger car. We assume that a household is in a good match when it adjusts its durables, but over time the match quality can 
break down according to a Poisson process with intensity $\theta$. Specifically, there is a state $q_{i t}$ that takes a value 1 when the household adjusts it durables and drops to zero with intensity $\theta$. The service flow is

$$
s_{i t}=q_{i t} d_{i t}
$$

In equilibrium, households with bad matches will adjust their durable stocks immediately. These match-quality shocks are therefore a source of inframarginal adjustments.

In summary, the household maximizes (1) subject to (2), (3), (4), (5), (6), (7), and (8). Aggregate durable expenditures are determined by the individual decision rules and the distribution of households over idiosyncratic state variables.

\subsection{Calibration}

We set

$$
u(c, s)=\frac{\left[(1-\psi)^{\frac{1}{\xi}} c^{\frac{\xi-1}{\xi}}+\psi^{\frac{1}{\xi}} s^{\frac{\xi-1}{\xi}}\right]^{\frac{\xi(1-\sigma)}{\xi-1}}-1}{1-\sigma} .
$$

$\xi$ is the elasticity of substitution between durables and non-durables. There is a range of estimates for this elasticity. Many housing and durable models choose an elasticity of 1 , which is consistent with estimates in Ogaki and Reinhart (1998) and the near-constant expenditure share of housing in the NIPA (Davis and Ortalo-Magné, 2011). However, housing and rent expenditure shares have trended up in the AHS, Census, and CEX survey data (Albouy et al., 2016), which is more in line with an elasticity below one. Further, studies allowing for non-homethic preferences tend to estimate below-unitary elasticities (Pakoš, 2011; Davidoff and Yoshida, 2013; Albouy et al., 2016). We choose an elasticity of $\xi=0.5$, which is at the lower end of these estimates. Choosing a lower value is conservative. To see this, suppose we used Leontief utility so that durables were in a fixed proportion to non-durables regardless of the user cost, then the dynamics of the desired durable stock would mimic the dynamics of non-durable consumption.

We set $\sigma=4$ implying an IES of $1 / 4$. This is at the lower end of the range typical in the literature. We need a low IES to match the small response of non-durable consumption to monetary policy shocks we measure in the data (see Section 3). The durable exponent $\psi$ is set to match the average ratio of the nominal values of the total durable stock (durable goods and private residen- 
tial structures) and annual non-durable consumption (non-durable goods and services excluding housing) since 1970 .

Like Berger and Vavra (2015), our calibration captures a broad notion of durables, which includes residential housing, autos, and appliances among other goods. While these goods differ in important respects, such as their depreciation rate and the probability of adjustment, they are all long-lasting and illiquid and purchases are lumpy and infrequent, features we stress in our analysis. Following this broad notion, our depreciation rate $\delta$ is the annual durable depreciation divided by the total durable stock in the BEA Fixed Asset tables, again averaged since 1970 . While $73 \%$ of the value of the total durable stock consists of residential housing, this component accounts for $23 \%$ of the total depreciation owing to the low depreciation rate of structures relative to cars and appliances. This explains why non-housing durables account for the majority (64\%) of spending on durables and are thus important in the determination of aggregate demand.

The fixed cost of adjustment, in combination with the depreciation rate, is a key determinant of the probability of adjustment of the durable stock. We set the fixed cost to target a weighted average of the annual adjustment probabilities of individual durable goods. The three components of the average are the probability that a household moves to a new dwelling (15\% Bachmann and Cooper, 2014), makes a significant addition or repair to their current dwelling (2.5\% in the PSID), or acquires a new or used car $(29.6 \%$ in the CEX). We attach a weight of 0.9 to the sum of housing moves and additions and repairs, and a weight of 0.1 to cars, based the the relative value of the housing stock and the car stock in the BEA fixed asset tables. This yields an annual adjustment probability of 0.19 . Note that we cannot simply sum the probabilities of adjustments across durable goods, since this would overstate the liquidity of the households' total durable position in our model.

Our calibration of the income process uses the estimates from Floden and Lindé (2001) converted to a continuous-time Ohrnstein-Uhlenbeck process. We set $\rho_{z}=\log (0.9136)$ and $\sigma_{\eta}=0.2158$.

We set the steady state net real interest rate $r$ to $2.34 \%$. This value is the average, ex post, real federal funds rate in terms of non-durables from 1970 to 2007. The borrowing spread $r^{b}$ is set to 0.017 based on the difference between the 30-year mortgage rate and the 10-year treasury bill rate over the same period. The discount rate $\rho$ is set to match the average liquid financial asset holdings net of mortgage and auto loans to annual GDP ratio since 1970 of $0.87 .{ }^{3}$ The borrowing

\footnotetext{
${ }^{3}$ We use the same set of assets as McKay et al. (2016) and Guerrieri and Lorenzoni (2017): Currency and checkable deposits, time and savings deposits, MMF shares, Treasury securities, agency securities, municipal securities,
} 
limit is set to $\lambda=0.8$ in line with a $20 \%$ down payment requirement.

The fraction of depreciation covered by maintenance in housing is $92 \%$ based on the sum of intermediate goods and services consumed in the BEA housing output table and PCE on household maintenance. For cars, PCE on motor vehicle maintenance and repair is $47 \%$ of depreciation. We sum maintenance costs for cars and housing and divide by durable depreciation to get $\chi=0.35 .^{4}$

Turning to operating costs, taxes on the housing sector, PCE on household utilities, and PCE on fuel oil and other fuels (excluding motor vehicle fuels) amount to $4.1 \%$ of the value of the housing stock. For cars, we find that PCE on motor vehicle fuels, lubricants, and fluids amounts to $22 \%$ of the value of the stock of vehicles. We sum the operating costs for cars and housing and divide by the total durable stock to obtain $\nu=0.048$.

\subsection{Estimating the Arrival Rate of Match-Quality Shocks}

The intensity of the match-quality shock, $\theta$, does not have a natural data counterpart that lends itself to calibration. We therefore estimate this parameter using PSID data and a variant of the structural estimation method developed by Berger and Vavra (2015) that allows for match-quality shocks. Since we largely follow their method, we only provide a brief overview here, with details relegated to Appendix B.

The estimation method centers on matching the probability of a durable adjustment as a function of the "durable gap" $\omega_{i t} \equiv d_{i t}^{*}-d_{i t}$, where $d_{i t}^{*}$ is the optimal durable stock based on the current state variables. Specifically, $d^{*}$ is the level of durables the household would adjust to if it were forced to adjust immediately. Intuitively, in a fixed-cost model the probability of adjustment should be greater the larger is the absolute gap, since the benefit of adjusting the durable stock is larger.

Gaps are easily computed in the model, since both the optimal durable choice $d_{i t}^{* \text { model }}$ and the current durable stock $d_{i t}^{\text {model }}$ are known. In the data, we only observe current durable holdings $d_{i t}^{\text {data }}$ directly. We infer data gaps using a set of observables $\mathbf{Z}_{i t}^{\text {data }}$, and the model-implied relationship between them and the optimal durable stock, $d_{i t}^{* \text { data }}=F^{\text {model }}\left(\mathbf{Z}_{i t}^{\text {data }}\right)$, where $F^{\text {model }}$ is the model's mapping from the observables to $d *$. We then minimize the distance between the hazard rate corporate and foreign bonds, and mutual fund shares.

${ }^{4} \chi$ is not a convex combination of $92 \%$ and $47 \%$ because the denominator includes depreciation from durables other than cars and housing. 
Table 1: Calibration of the Full Model

\begin{tabular}{|c|c|c|c|}
\hline Parameter & Name & Value & Source \\
\hline \multicolumn{4}{|c|}{ Parameters of the Household's Problem } \\
\hline$\rho$ & Discount factor & 0.104 & Net Assets/GDP $=0.87$ \\
\hline$\sigma$ & Inverse IES & 4 & See Section 3 \\
\hline$\psi$ & Durable exponent & 0.585 & $\mathrm{~d} / \mathrm{c}$ ratio $=2.64$ \\
\hline$\xi$ & Elas of substitution & 0.5 & See text \\
\hline$r$ & Real interest rate & 0.023 & Annual real FFR \\
\hline$r^{b}$ & Borrowing spread & 0.017 & Mortgage T-Bill spread \\
\hline$\delta$ & Depreciation rate & 0.068 & BEA Fixed Asset \\
\hline$f$ & Fixed cost & 0.187 & Ann. adjustment prob $=0.19$ \\
\hline$\theta$ & Intensity of match-quality shocks & 0.155 & See Section 2.3 \\
\hline$\chi$ & Required maintenance share & 0.35 & See text \\
\hline$\nu$ & Operating cost & 0.048 & See text \\
\hline$\rho_{y}$ & Income persistence & -0.090 & Floden and Lindé (2001) \\
\hline$\sigma_{\eta}$ & Income st. dev. & 0.216 & Floden and Lindé (2001) \\
\hline$\lambda$ & Borrowing limit & 0.8 & $20 \%$ Down payment \\
\hline \multicolumn{4}{|c|}{ General Equilibrium Parameters } \\
\hline$G / Y$ & Steady state govt share & 0.2 & Convention \\
\hline$\zeta$ & Inverse durable supply elasticity & 0.049 & See Section 4 \\
\hline$\kappa$ & Phillips curve slope & 0.48 & See Section 4 \\
\hline$\phi_{\pi}$ & Real rate response to inflation & 0.5 & Convention \\
\hline
\end{tabular}


of adjustment in model and data, $h^{\text {model }}\left(\omega^{\text {model }}\right)-h^{\text {data }}\left(\omega^{\text {data }}\right)$ where $h(\omega)$ is the probability of adjusting given a gap $\omega$, as well the as the distance between the distribution of gaps, $f^{\text {model }}\left(\omega^{\text {model }}\right)-$ $f^{\text {data }}\left(\omega^{\text {data }}\right)$ where $f(\omega)$ is the density at gap $\omega$. Like Berger and Vavra (2015), we allow for measurement error in $\mathbf{Z}_{i t}^{\text {data }}$.

The arrival rate of the match-quality shock, $\theta$, is primarily identified by the hazard of adjustment for small gaps. Intuitively, at small gaps the household should be relatively far from an adjustment threshold due to the fixed cost, whereas adjustments at large gaps likely reflect that the household crossed an adjustment threshold. Most of the adjustments at small gaps are therefore attributed to the match-quality shock. As we vary $\theta$, we re-calibrate the discount rate $\rho$, the fixed cost $f$, and the preference for durables $\psi$ to match the same targets for net assets, the probability of adjustment, and the durable-stock-to-non-durable-consumption ratio.

Our set of observables from the PSID, $\mathbf{Z}_{i t}^{\text {data }}$, are net liquid assets $a_{i t}$, the value of the durable stock $d_{i t}$, and annualized consumption expenditures over the following wave $\bar{c}_{i, t, t+2}$. We compute these same lagged and time-aggregated objects in the model to estimate $d_{i t}^{* \text { model }}=\beta_{0}+\beta_{1} a_{i t}^{\text {model }}+$ $\beta_{2}\left(a_{i t}^{\text {model }}\right)^{2}+\beta_{3} d_{i t}^{\text {model }}+\beta_{4} \bar{c}_{i, t, t+2}^{\text {model }}+\beta_{5} \frac{d_{i t}^{\text {model }}}{\bar{c}_{i, t, t+2}^{\text {model }}}+\epsilon_{i t}$ using model population weights. This function explains more than $98 \%$ of the variation of $d_{i t}^{* \text { model }}$. We then use these estimates to predict $d_{i t}^{* \text { data }}$ using the observables in the data.

We use direct information from the PSID on durable adjustments. For housing we use the answer to whether the household has moved along with the recorded date of moving, and whether the household made a major addition or repair to the home. If at least one move or addition/repair takes place since the previous wave, then we record this as a durable adjustment. Similarly, for up to three cars the PSID records whether they were acquired less than three years ago along with the acquisition dates. If any car acquisition occurred after the previous wave, then we record this as a car adjustment. Just like our total adjustment frequency, we weight a housing adjustment by 0.9 and car adjustments by 0.1 . We also time-aggregate the hazard of adjustment in the model to two years, in accordance with the wave length of the PSID.

Figure 1 plots the model- and data-implied hazards of adjustment conditional on the durable gap at the optimal parameter estimate, $\theta=0.155$. The bootstrapped $95 \%$ confidence band is [0.154,0.156], based on sampling households from the PSID with replacement. The model accounts well for the upward-sloping hazard and explains $79 \%$ of the variation in the hazard rate. Note that 


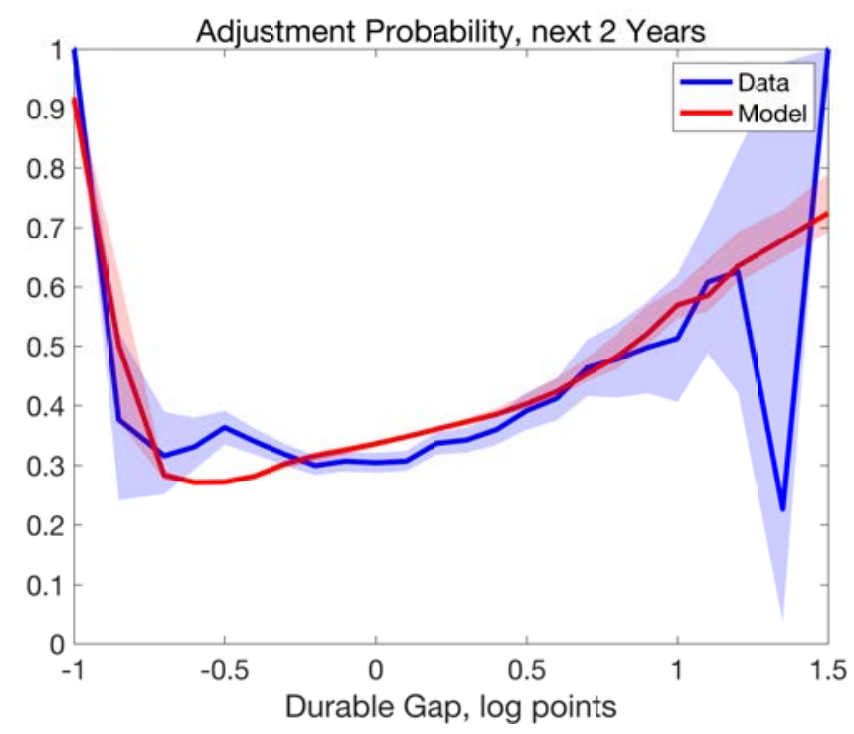

Figure 1: Hazard of adjustment conditional on the durable gap $\omega=d^{*}-d$, where $d^{*}$ is the optimal durable choice conditional on adjusting and $d$ the initial durable stock. Shaded areas are $95 \%$ confidence bands.

the probability of adjustment is substantial in both model and data for even small gaps, suggesting that the match-quality shock is important in matching the data. ${ }^{5}$ Indeed, our estimate implies that $74 \%$ of all adjustments are due to the match-quality process. This split between matchquality shocks and adjustments due to depreciation or income fluctuations roughly coincides with the stated reasons for moving house in the March CPS Supplement (see Appendix Table 5).

In the next section we show that the idiosyncratic match-quality shocks not only help match the microeconomic hazard of adjustment, but also help match the interest rate elasticity of durable demand.

\section{The Response of Durable Demand to Monetary Policy}

In this section we estimate the response of total durable expenditure and the extensive margin of durable adjustment to identified monetary policy shocks and we compare these empirical benchmarks to the model's prediction. This is an important check on the model because standard fixed-cost models imply that durable demand is extremely sensitive to incentives for intertemporal substitution (House, 2014). We show and explain how operating costs and match-quality shocks

\footnotetext{
${ }^{5}$ We estimate larger adjustment probabilities at small gaps than Berger and Vavra (2015) do because we follow a different approach to identifying adjustments in the data. Berger and Vavra exclude durable adjustments smaller than $20 \%$ of the value of the durable stock in part to filter out idiosyncratic moves across location.
} 
substantially reduce the interest elasticity of durable demand and bring it in line with the data.

\subsection{Empirical Benchmark}

We estimate the response of total durable expenditure, $x_{t}$, and the extensive margin of durable purchases to an identified monetary policy shock. ${ }^{6}$ To measure the extensive margin, we construct time series for the adjustment probabilities of housing and cars using micro-data from the PSID and the CEX. ${ }^{7}$ We also estimate the response of the real interest rate in terms of non-durable goods $r_{t}$, aggregate income $Y_{t}$, and the relative durable price $p_{t}$. We then feed the income and price paths $\left(Y_{t}, r_{t}, p_{t}\right)$ into the model to determine model-implied path for durable expenditure, $x_{t}^{\text {model }}$, and the extensive margin, $\operatorname{Pr}(\operatorname{adjust} x)_{t}^{\text {model }}$. We will say that the model-implied interest elasticity of durable demand is reasonable if $x_{t}^{\text {model }}$ is "close" to the empirical $x_{t}$, and similarly for the extensive margin. The logic of this strategy is that a model that is a good description of the household block of the economy should match the observed equilibrium quantity response in reaction to the observed equilibrium price response.

We use monetary shocks from Romer and Romer (2004), extended by Wieland and Yang (2017), for 1969Q1-2007Q4. We estimate local projections,

$$
z_{t+k}=\sum_{m=0}^{M} \beta_{k, m} \epsilon_{t-m}+\sum_{l=1}^{L} \gamma_{k, l} z_{t-l}+\sum_{d=1}^{3} \delta_{d} t^{d}+\eta_{t}, \quad k=0, \ldots, H
$$

where $z_{t}$ is the outcome variable, $\epsilon_{t}$ is the monetary shock, and $t^{d}$ is a time trend. The impulse response function is the sequence $\left\{\beta_{k, 0}\right\}_{k=0}^{H}$. Standard errors are Newey-West.

The top-left panel of Figure 2 displays an economically sizable and statistically significant decline in the annualized, ex post, real federal funds rate in terms of non-durables given a one-standard deviation expansionary monetary policy shock. The top-right panel shows that real national income (GDP) increases with a lag. In the center-left panel the relative durable price displays a small increase but remains close to the steady state throughout the first four years. ${ }^{8}$

\footnotetext{
${ }^{6}$ Appendix $\mathrm{C}$ details the construction of the variables used in this analysis.

${ }^{7}$ We construct the annual time series for the probability of moving to a different residence using PSID data from 1969-1997 following Bachmann and Cooper (2014). Bachmann and Cooper (2014) show that the moving probability from the PSID is in line with the shorter time series from the CPS March Supplement and the AHS. For the probability of buying a car we use CEX data from 1980-2007. Appendix Figure A.1 shows that CEX car expenditures aggregate well to NIPA expenditures. See Appendices C.2 and C.3 for details.

${ }^{8}$ Appendix Figure A.2 shows that while the relative durable price is close to flat, both non-durable and durable prices increase with some lag following an expansionary monetary policy shock.
} 
The center-right panel displays the cumulative real durable expenditure. (Thus, its slope is the impulse response for real durable expenditure.) It peaks at $16 \%$ after 11 quarters. We interpret this figure as a summarizing the real effects of a monetary policy shock on real durable expenditure, taking into account the lags in the data. Accordingly, one can view a one-standard-deviation expansionary monetary policy shock as raising durable expenditures by $16 \%$. By comparison, cumulative non-durable consumption excluding rent increases by $3 \%$. Durable expenditure makes up $22.9 \%$ of total consumption excluding rent, so the durable component accounts for $61 \%$ of the total increase of consumption following a monetary shock.

In the bottom-left panel we show that the cumulative probability of moving home peaks at $22.3 \%$ after three years ${ }^{9}$ and in the bottom-right panel the cumulative probability of acquiring a car peaks at $9.2 \%$ after eight quarters.

The observed impulse response functions show hump-shaped responses to the monetary shock. Matching these dynamics is a well-known challenge and our model is no exception. What is important for our analysis is the overall magnitude of intertemporal shifting of durable expenditure in response to monetary policy shocks. Hence, our metric is to compare the peak of the cumulative impulse response function for durable expenditure and the extensive margin in the data with the same cumulative impulse response function in the model. In this way we ask the model to match the overall magnitude of the response of total durable demand and households' willingness to shift their durable adjustments through time. The implications of this expenditure shifting for intertemporal demand management and the relevant opportunity costs for durable adjustments will operate in a similar manner even if they occur later in time.

\subsection{Simulated Monetary Policy Shocks}

To assess the sensitivity of durable demand to monetary policy shocks in the model we feed the mean impulse response function for the real interest rate, $r_{t}$, real GDP, $Y_{t}$, and the relative durable price, $p_{t}$, into the household decision problem of Section 2 starting in steady state. We assume that these paths come as a surprise at $t=0$, but are subsequently known with certainty, and return to steady state after 16 quarters. ${ }^{10}$ We then construct the model-implied cumulative real

\footnotetext{
${ }^{9}$ The annual impulse response function is multiplied by four so that the cumulative response is comparable to the cumulative impulse response function for quarterly series.

${ }^{10}$ We found that incorporating the uncertainty around the estimated price and income responses into our model simulation made little difference to the dynamics of durable demand.
} 

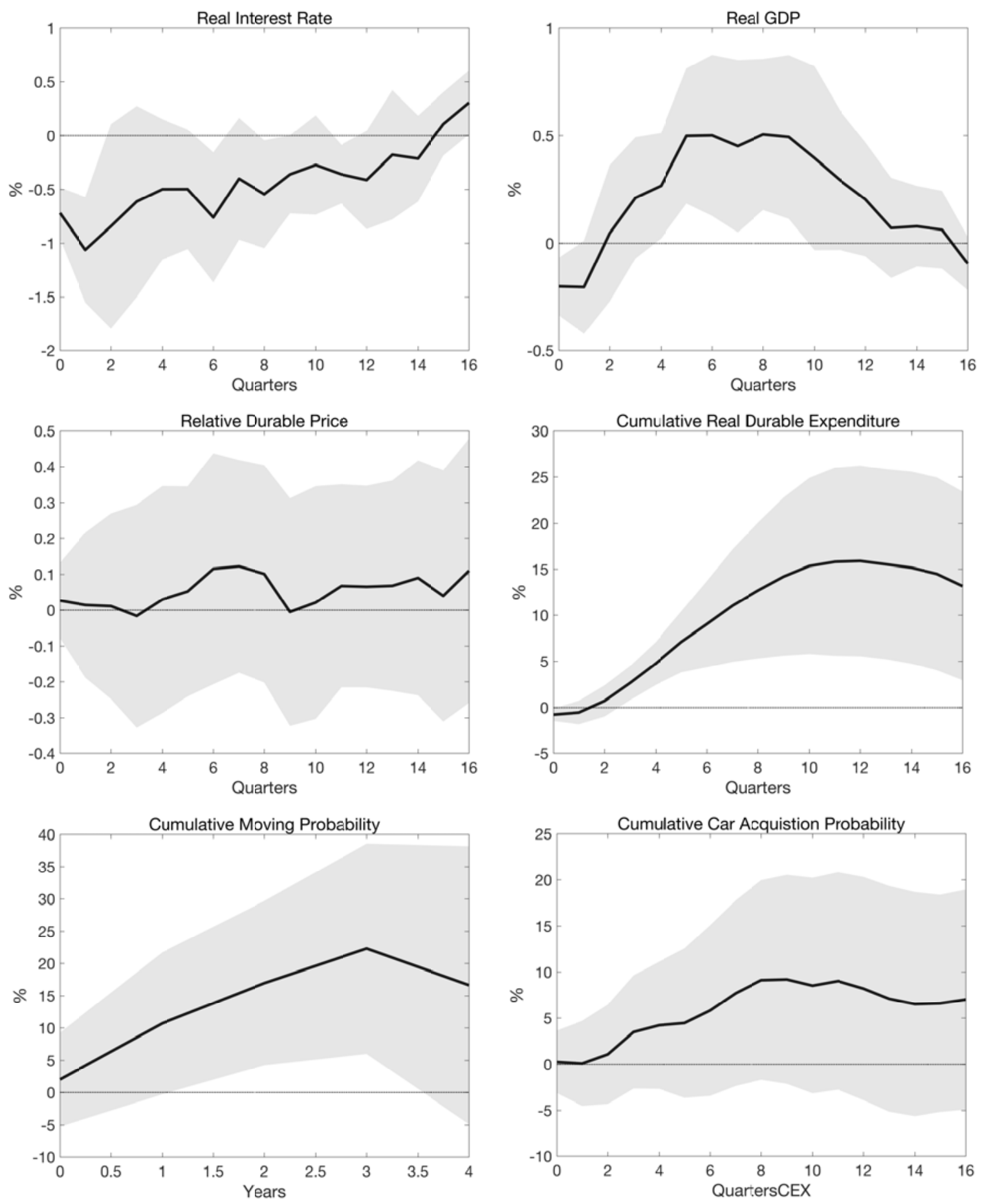

Figure 2: Impulse response function of the real interest rate in terms of non-durables (top-left panel), real GDP (top-right), the relative durable price (center-left), cumulative real durable expenditure (center-right), cumulative probability of moving house (bottom-left), and cumulative probability of buying a car (bottom-right), to a one-standard-deviation Romer and Romer monetary policy shock. 
$\underline{\text { Durables }}$

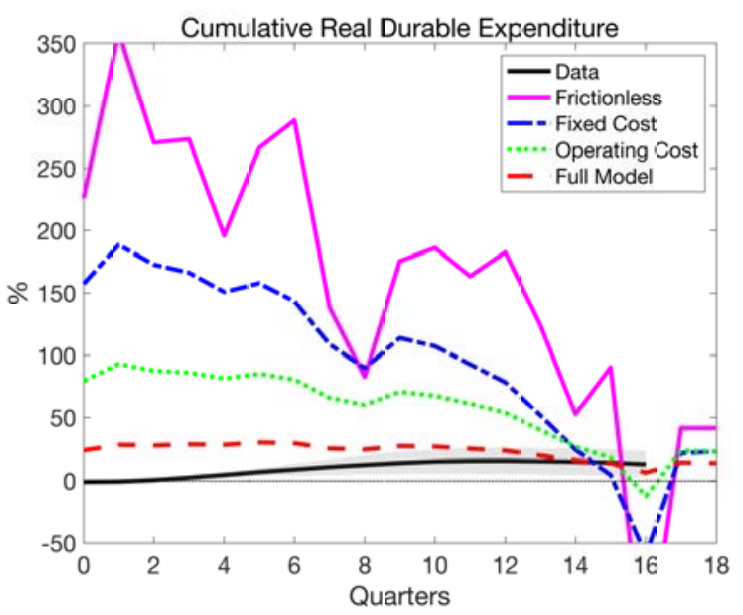

Non-Durables

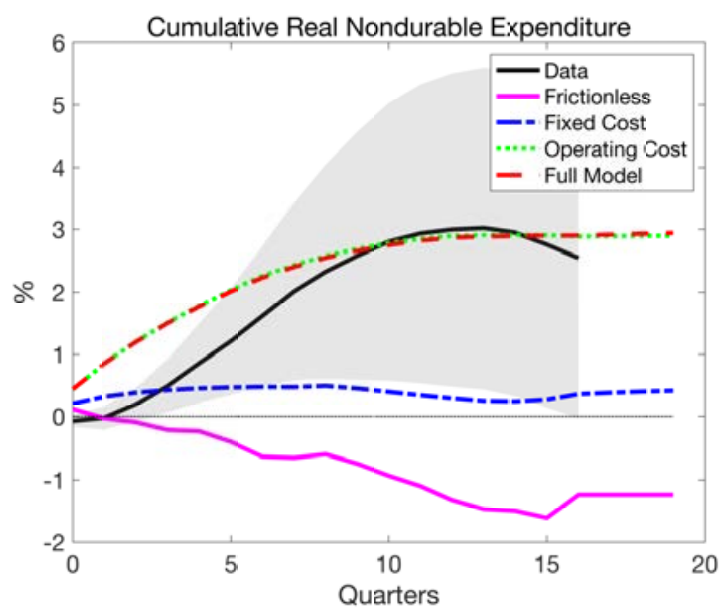

Figure 3: Model simulations feeding in observed paths for $\left(Y_{t}, r_{t}, p_{t}\right)$. The panes show the cumulative response of durable expenditures (left) and non-durable spending (right). Each panel shows the frictionless model, the model with only fixed costs, the model with fixed costs and operating costs, and the full model.

durable expenditure and compare it to our empirical estimate. We conduct this simulation for several versions of our model to show the contributions of operating costs and match-quality shocks. We start with a frictionless model that omits idiosyncratic risk, operating costs and all forms of adjustment frictions. We then add idiosyncratic risk, borrowing constraints, and fixed costs. Next, we add operating costs and finally match-quality shocks to arrive at our full model. Each of the models with fixed costs is calibrated to match the same durable-to-non-durable-consumption ratio, steady state adjustment probability, and net-liquid-assets-to-GDP ratio. ${ }^{11}$

The left panel of Figure 3 plots the results. In the frictionless model, cumulative real durable expenditures peaks at 359\%, 20 times more than their peak response in the data. ${ }^{12}$ The fixed-cost model only fares slightly better than the frictionless model, consistent with the insights in House (2014). Including operating costs reduces the peak response to $93 \%$, which halves the discrepancy with the data to a factor of 6 . With the addition of match-quality shocks, the full model comes even closer to matching the interest-elasticity of durable demand in the data. The peak real durable

\footnotetext{
${ }^{11}$ In the fixed-cost model the discount rate, durable preference, and fixed cost are $\rho=0.085, \psi=0.463 f=0.018$. In the model with operating costs they are $\rho=0.086, \psi=0.545 f=0.011$.

${ }^{12}$ Models with high interest elasticity of durable demand will show very little fluctuation in the durables real interest rate in equilibrium (Barsky et al., 2007). Appendix Figure A.3 plots the impulse response for the durables real interest rate, which displays an economically sizable, persistent, and statistically significant decline following an expansionary monetary policy shock.
} 
response is $30 \%$ compared to $16 \%$ in the data.

In the right panel of Figure 3 we show that both the frictionless and the fixed-cost model also have difficulty matching the cumulative expenditure on non-durables. Households are spending so much on durables that they end up cutting back on non-durables. By contrast, the models including operating costs provide a good quantitative match. This figure motivated our choice of a relatively low intertemporal elasticity of substitution in Section 2.

The large interest elasticity of durable demand in the fixed-cost model is almost entirely accounted for by the extensive margin response (181 of the 189 percentage point peak response). We now show that the willingness of households to shift the timing of their durable adjustments in our full model aligns well with the observed extensive margin responses for cars and housing. We consider two different calibrations to tailor the model to cars and housing, respectively. The primary difference is in the calibrations is the depreciation rate. ${ }^{13}$ As above, we simulate the impulse response for the extensive margin by feeding the empirical impulse responses of $Y_{t}, r_{t}$, and $p_{t}$ into the model. ${ }^{14}$ Table 2 has the results. Starting with the fixed-cost model, the extensive margin of housing adjustments responds 13 times more in the model than in the data while the extensive margin of car purchases is 5 times larger than in the data. The low depreciation rate of structures accentuates the distance between model and data relative to our baseline, whereas the high depreciation rate of cars attenuates it. Including operating costs dampens the extensive margin response for housing, but has little effect on the response of car adjustments. Finally, in our full model including match-quality shocks the magnitude of the extensive margin response is close to the empirical point estimates and well within the $95 \%$ confidence interval for both cars and housing.

\footnotetext{
${ }^{13}$ Housing structures depreciate at a much slower rate, $2 \%$ per year, while cars depreciate at a much higher rate, $20 \%$ per year, than the value-weighted durable stock. The probability of adjustment is also higher for cars $(7.4 \%$ quarterly) than for housing ( $15 \%$ annually), and households own more housing wealth $(d / c=1.92)$ than car wealth $(d / c=0.201)$. We recalibrate the discount rate $\rho$, the fixed cost $f$, and the durable exponent $\psi$ to match these targets, as well as a net-liquid-asset-to-GDP ratio of 0.92 for housing and 1.31 for cars. When we include matchquality shocks, $74 \%$ of all adjustments will come from the match-quality process, which is the same fraction as in our estimated model for all durables. This requires $\theta=0.12$ for housing and $\theta=0.22$ for cars. We only subtract the collateralized loans for the durable we calibrate to. We also allow for a higher borrowing spread $r^{b}=0.03$ in the car model based on the average spread of four-year car loans with treasury bonds.

${ }^{14}$ We use a different relative price response: for housing we use the relative price of housing to non-durable consumption, whereas for cars we use the relative price of cars. Appendix Figure A.4 shows that these relative prices behave similarly to the relative price for all durables.
} 
Table 2: Peak Cumulative Extensive Margin Response (percent change in frequency of adjustment)

\begin{tabular}{|c|c|c|}
\hline & Housing & Cars \\
\hline $\begin{array}{l}\text { Data } \\
\qquad\left[\begin{array}{ll}95 \% & C I\end{array}\right]\end{array}$ & $\begin{array}{c}22.3 \\
{[6.0,38.6]}\end{array}$ & $\begin{array}{c}9.2 \\
{[-2.1,20.6]}\end{array}$ \\
\hline Fixed Cost & 287.6 & 45.0 \\
\hline Operating Cost & 89.2 & 47.9 \\
\hline Full Model & 17.0 & 8.9 \\
\hline
\end{tabular}

\subsection{The Roles of Match-Quality Shocks and Operating Costs}

Why do operating costs and match-quality shocks reduce the sensitivity of durable demand to interest rate changes? Match-quality shocks are a source of inframarginal adjustments. We target a certain probability of adjustment in total and by associating more of these adjustments with the match-quality shock, fewer are attributed to households that have hit an $(S, s)$ band. Therefore including match-quality shocks means there are fewer households near the adjustment thresholds who can be induced to adjust by monetary policy. ${ }^{15}$ To demonstrate this role of match-quality shocks, Figure 4 shows the density of durable holdings in the fixed-cost model and the full model for a particular level net liquid assets and idiosyncratic income. The vertical dashed lines show the adjustment thresholds. The mass of households near the adjustment threshold is substantially smaller in the full model.

Operating costs are a component of the user cost of durables that is not sensitive to interest rates and including them stabilizes the user cost and therefore durable demand. In Figure 4, the adjustment thresholds shift to the right in response to monetary stimulus, but much less so in the full model. Operating costs matter more for housing than cars in Table 2 because the depreciation rate is relatively low for housing so adding operating costs has a big effect on the level of the user cost.

\footnotetext{
${ }^{15}$ The logic of how match-quality shocks affect the extensive margin response of durable demand has antecedents in the literature on price setting (see Golosov and Lucas, 2007; Midrigan, 2011; Nakamura and Steinsson, 2010; Alvarez et al., 2016).
} 

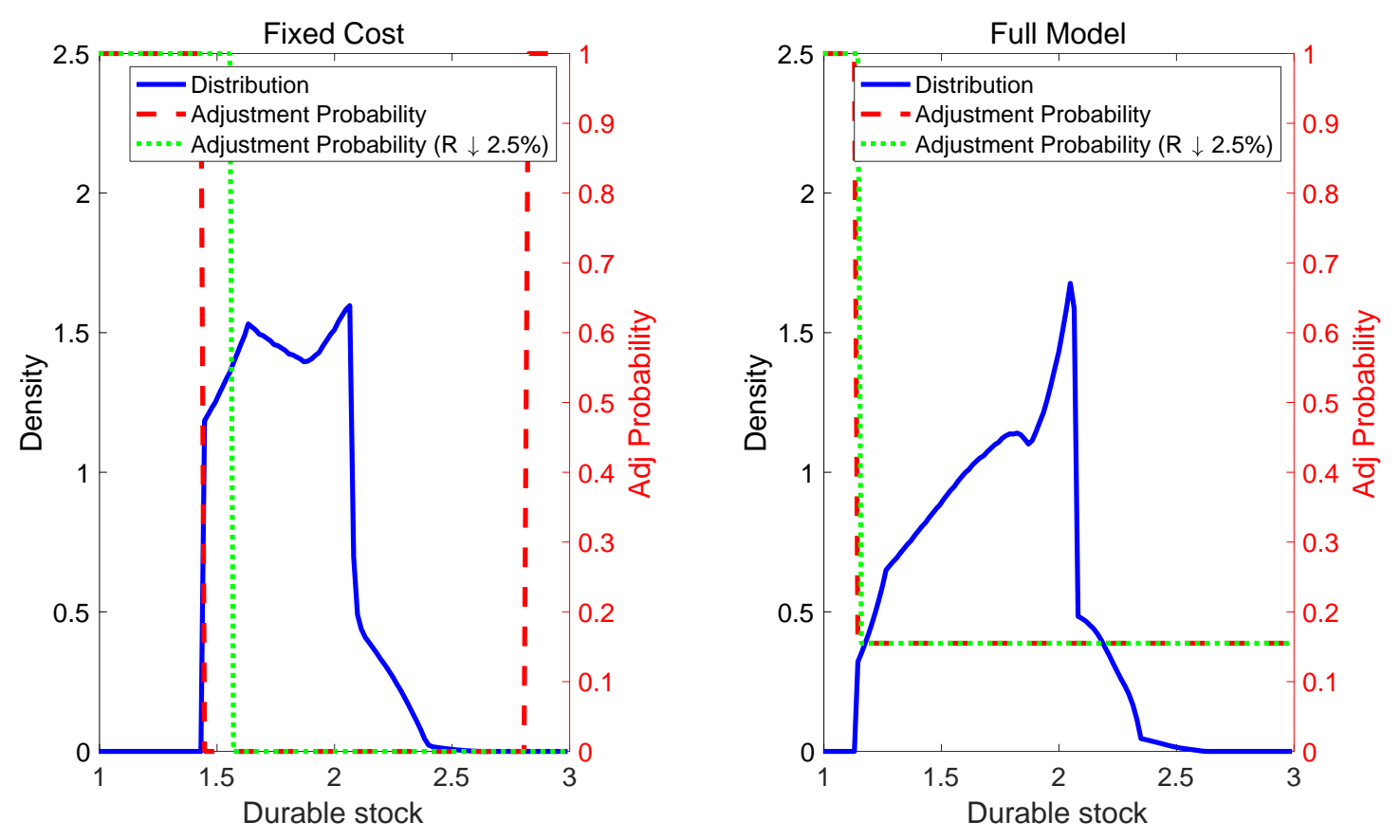

Figure 4: Distribution of households over durable holdings. The distributions shown are conditional on net liquid assets of 1.99 and and gross income of 0.93 . Net liquid assets are measured as $a-\lambda d$. The adjustment thresholds are shown at their steady state positions and in response to a 2.5 p.p. cut in the interest rate for the current quarter.

\subsection{Quasi-Experimental Evidence}

Monetary policy primarily stimulates durable demand by reducing the real interest rate in terms of durables. There is also quasi-experimental evidence on how the extensive margin of durable demand responds to the real interest rate. Mian and Sufi (2012) and Baker et al. (2019) analyze the response of auto purchases to the Cash-for-Clunkers program and anticipated sales tax increases, respectively. These policies can be translated into a low real interest rate in terms of durables, as the after-tax durable price is expected to increase both when Cash-for-Clunkers ends and when the sales tax rises. We will translate the results of these two studies into an interest elasticity of the extensive margin and compare to our model's predictions.

Baker et al. (2019) estimate a cumulative 12.7 percent increase in monthly auto sales leading up to a 1 percentage point increase in sales tax (Table 3, Col. 1). This implies an annualized 12 percent decrease in the real interest rate for cars in the month before the tax increase so the elasticity of the extensive margin of auto sales to interest rates is about $12.7 / 12=1.1$. Our conversion of the estimates for the Cash-for-Clunkers program in Mian and Sufi (2012) yields an elasticity in the 
range of 4.3 to $5 .^{16}$

Table 3: Implied Interest Rate Elasticity for Car Purchases

\begin{tabular}{c|c} 
Data & \\
Baker et al. (2019) & 1.1 \\
Mian and Sufi (2012) & $4.3-5.0$ \\
Model & \\
Fixed Cost & 47.7 \\
Operating Cost & 35.2 \\
Full Model & 3.8 \\
\hline
\end{tabular}

In our model calibrated to cars we calculate the elasticity based on the impact effect of a one month drop in the real interest in durables. As shown in Table 3, our model produces an elasticity of 3.8, which is between those derived from Baker et al. and Mian and Sufi. The table shows that operating costs and match-quality shocks are crucial in matching this evidence. These studies also document a reversal in demand after the real interest rate for cars returns to normal. This intertemporal shifting of durable demand also occurs in our model.

\section{General Equilibrium Model}

So far we have analyzed the durable spending response for an observed monetary policy path using the associated income and price responses. To study alternative monetary policy experiments we must now specify how prices and income are determined in equilibrium.

\subsection{Labor Supply, Production, and Aggregate Supply}

We adapt the standard sticky-wage environment developed by Erceg et al. (2000) to allow for uninsured idiosyncratic labor productivity. Each household $i$ supplies a continuum of differentiated

\footnotetext{
${ }^{16}$ Mian and Sufi (2012) argue that cross-city variation in Cash for Clunkers explains between 340k and 398k of additional autos sold. New vehicle sales in April and May were on average 833,000. Used vehicle sales were $36.5 \mathrm{~m}$ and $35.5 \mathrm{~m}$ in 2008 and 2009, implying an average monthly sales volume of $2 \mathrm{~m}$. Total baseline vehicle sales are then $2.833 \mathrm{~m}$. The increase in vehicle sales estimated by Mian and Sufi then corresponds to $340 k / 2.833 m-1=12 \%$ to $398 k / 2.833 m-1=14 \%$ rise. Total expenditure on Cash for Clunkers was $\$ 3 \mathrm{bn}$, and the vehicle stock in 2008 was worth $\$ 1279.4 \mathrm{bn}$ at replacement cost. This translates into a $3 / 1279.4=0.23$ percent reduction in the replacement price, or 2.8 percent expressed as an annual rate. Therefore, the elasticity ranges from $12 / 2.8=4.3$ to $14 / 2.8=5.0$.
} 
labor of type $j \in[0,1]$, with hours denoted $n_{i j t}$. We extend the household preferences with an additively separable disutility of labor supply

$$
E_{0} \int_{t=0}^{\infty} e^{-\rho t}\left[u\left(c_{i t}, s_{i t}\right)-\bar{u}_{c, t} \int_{0}^{1} v\left(n_{i j t}\right) \mathrm{d} j\right] \mathrm{d} t .
$$

where we use the modifier on the disutility of labor, $\bar{u}_{c, t}=\int_{0}^{1} \frac{\partial u\left(c_{i t}, s_{i t}\right)}{\partial c_{i t}} \mathrm{~d} i$, to eliminate wealth effects on labor supply. ${ }^{17}$ Labor supply is determined by a set of unions as described below so the household takes labor supply and labor income as given. As the disutility of labor is additively separable and labor income is outside the household's control, the decision problem we analyzed in the previous section is unchanged.

Final goods are produced with a technology that is linear in labor, $Y_{t}=Z_{t} L_{t}$, where $Z_{t}$ is TFP and $L_{t}$ is an aggregate of labor supply given by

$$
L_{t}=\left(\int_{0}^{1} l_{j t}^{\frac{\varphi-1}{\varphi}} \mathrm{d} j\right)^{\frac{\varphi}{\varphi-1}}
$$

where

$$
l_{j t}=\int_{0}^{1} z_{i t} n_{i j t} \mathrm{~d} i
$$

We now interpret $z_{i t}$ as idiosyncratic labor productivity. The final good is produced by a representative firm. Prices are flexible and equal to nominal marginal cost: $P_{t}=W_{t} / Z_{t}$, where $W_{t}$ is the price index associated with the aggregator $L_{t}$. The real wage is then $W_{t} / P_{t}=Z_{t}$. In most of our analysis, $Z_{t}$ is constant and equal to 1 .

The final good is used for several purposes: non-durable consumption, an input in the durable production, and government consumption. Appendix E shows the market-clearing conditions.

We obtain an upward-sloping Phillips curve through sticky nominal wages. A continuum of unions set the wage, $W_{j t}$, of each type of labor. The union maximizes the equally-weighted utility of the households subject to a Rotemberg-style adjustment cost of $\frac{\Phi}{2} \bar{u}_{c, t} L_{t}\left(\mu_{j t}\right)^{2}$, where $\Phi$ is a parameter that controls the strength of the nominal rigidity and $\mu_{j t}$ is the growth rate of $W_{j t}$ such that $\operatorname{dln} W_{j t}=\mu_{j t} \mathrm{~d} t$. Among union workers supplying type $j$, all labor is equally rationed, $n_{i j t}=l_{j t}$. In a symmetric equilibrium, all workers supply $L_{t}$ units of labor.

\footnotetext{
${ }^{17}$ We do so for computational convenience. The wealth effect in labor supply introduces an additional loop in finding the market-clearing prices and quantities since it creates a feedback from distribution of marginal utility to the real interest rate in the policy rule. In unreported results we have found that this wealth effect is not quantitatively important for output dynamics.
} 
Appendix E presents the union's problem and shows that the log-linearized symmetric equilibrium gives rise to the following Phillips curve

$$
\dot{\pi}_{t}=\rho \pi_{t}-\kappa\left(\frac{Y_{t}-\bar{Y}}{\bar{Y}}-\frac{Z_{t}-\bar{Z}}{\bar{Z}}\right),
$$

where $\pi_{t}=\frac{\mathrm{d} \ln P_{t}}{\mathrm{~d} t}$, and $\bar{Y}$ and $\bar{Z}$ are the steady state values for output and TFP, respectively.

The durable good is produced by a unit measure of perfectly competitive firms using the production function,

$$
X_{t}=v Z_{t}^{\zeta} M_{t}^{1-\zeta} H_{t}^{\zeta}
$$

where $X_{t}$ is the production of durables, $M_{t}$ is the input of the non-durable good, $H_{t}$ is the input of land, and $v$ is a constant. A constant flow $\bar{H}$ of land is made available and sold by the government at a competitive price. $Z_{t}$ enters the production function here in a manner that is "land-augmenting" so that the long-run relative price of durables is unaffected by permanent TFP shocks. The first order conditions of this problem lead to a relative price of

$$
p_{t}=(1-\zeta)^{-1} v^{-\frac{1}{1-\zeta}}\left(\frac{X_{t}}{Z_{t} \bar{H}}\right)^{\frac{\zeta}{1-\zeta}},
$$

where $X_{t}$ is aggregate durable goods production. Thus, $(1-\zeta) / \zeta$ is the supply elasticity of the durable good.

\subsection{Government}

Monetary policy is governed either by an interest rate rule,

$$
r_{t}=\bar{r}+\phi_{\pi} \pi_{t}+\varepsilon_{t}
$$

where $\varepsilon_{t}$ is an exogenous shock, or equal to an exogenous path for the real interest rate as specified below.

Fiscal policy consists of a constant debt policy,

$$
A_{t}=\int_{0}^{1} a_{i t} \mathrm{~d} t=\bar{A}
$$

We assume that the government levies taxes proportional to $z_{i t}$ where the tax rate $\bar{\tau}_{t}$ is set to satisfy the government budget constraint so we have

$$
y_{i t}=\left(Y_{t}-\bar{\tau}_{t}\right) z_{i t}
$$


and the period-by-period government budget constraint is

$$
\bar{\tau}_{t}=r_{t} \bar{A}+G
$$

where $G$ is a constant level of government consumption. ${ }^{18}$ Government consumption plays very little role in our analysis, but we include it because it is a component of aggregate demand that is not sensitive to monetary policy.

\subsection{Calibration}

We calibrate the inverse supply elasticity of durable goods to $\frac{\zeta}{1-\zeta}=0.049$. Residential investment is on average $36 \%$ of broad durable consumption expenditures (NIPA Table 1.1.5, 1969-2007). New permanent site structures account for $58 \%$ of residential investment (NIPA Table 5.4.5). Davis and Heathcote (2007) report that $11 \%$ of sales of new houses reflect the value of land. Therefore payments for new land amount to a little over $2 \%$ of the expenditure on durables. However, Davis and Heathcote (2007) also report that the existing stock of housing is paired with more valuable land and land accounts for $36 \%$ of the value of the housing stock, which is substantially larger than the $11 \%$ share in new housing. In our model, durables trade at a single price so there is no distinction between the cost of creating new durables and the value of the stock. We therefore take the mid-point of $11 \%$ and $36 \%$, which implies that payments to land account for $5 \%$ of expenditure on durables. We set $v$ so as to normalize the relative price to one in steady state.

An elastic supply of durable goods is consistent with the lack of a relative price response in Figure 2. An elastic supply of durable goods also finds some support from Goolsbee (1998) and House and Shapiro (2008) who present evidence on the response of capital goods prices to policies that stimulate investment demand. House and Shapiro find little evidence of a price response and argue for a high supply elasticity. Goolsbee argues for less elastic supply in general, but for the categories of goods that also serve as consumer durables (autos, computers, and furniture) he finds little price response.

The slope of the Phillips curve is 0.48. Note that the slope of the Phillips curve is expressed in terms of the change in annualized inflation for a unit of the output gap per year so we would need to divide by 16 to compare to a quarterly discrete-time model, which yields a slope of 0.48/16 $=0.03$.

\footnotetext{
${ }^{18}$ The government also raises a small amount of revenue from selling land. In steady state this amounts to $0.5 \%$ of GDP. For computational convenience we assume this revenue finances an independent stream of spending.
} 
That value is squarely in the middle of empirical estimates (Mavroeidis et al., 2014).

We normalize steady state income to $\bar{Y}=1$, which implies $v^{\prime}(1)=\frac{\varphi-1}{\varphi}$. Because we linearize the Phillips curve, $v^{\prime \prime}(\bullet)$ is already captured by the slope of the Phillips curve.

\section{$5 \quad$ Effects of Monetary Policy with Lumpy Durables}

We now turn to our main results. In this section we specify monetary policy in terms of paths for the real interest rate, which can be interpreted in terms of an implicit policy for the nominal rate. ${ }^{19}$ In Section 6 and Appendix D.6 we show that the results in this section are robust to endogenous movements in real interest rates through inflation and the interest rate rule.

\subsection{Forward Guidance is Less Powerful than Contemporaneous Rates}

In the presence of fixed adjustment costs, one effect of monetary stimulus is to bring forward durable adjustments to the present that would otherwise have occurred in the future. In choosing to accelerate an adjustment, a household is giving up the interest on savings that it would have earned from the present until the adjustment would have otherwise occurred. Short-term interest rates are particularly important to this decision because households that are near the adjustment threshold are likely to adjust their durables soon even in the absence of stimulus. As a result, lumpy durables are an effective way to mitigate the "forward guidance puzzle" (Del Negro et al., 2015; McKay et al., 2016), whereby promises of lower interest rates arbitrarily far in the future have the same output effect today as contemporaneous interest rate cuts.

To demonstrate that current interest rates are more powerful in stimulating durable demand than future interest rates, we simulate two different paths for the real interest rate. Each path cuts the interest rate by 1 percentage point (annualized) for a single quarter, but the paths differ in the timing of the cut. ${ }^{20}$ The first path cuts the current rate between periods 0 and 1 , the second cuts the rate between quarters 8 and 9. Fixing the real interest rate path is obviously not a realistic description of monetary policy, but the spirit of this analysis is to demonstrate in the most transparent way how the demand-side of the economy functions. Households perfectly foresee the future interest rates and the evolution of the economy.

\footnotetext{
${ }^{19}$ For the experiments we consider, the nominal interest rate paths track the real interest rate paths quite closely because the inflation responses are small. See Figure A.5 in the appendix.

${ }^{20}$ In this and all subsequent experiments we simulate the model in quarterly time steps.
} 
Figure 5 shows the results. The output responses shown in the figure are overwhelmingly driven by durable demand as opposed to non-durable demand. The reduction in interest rates motivates households to accelerate their adjustments in the quarter in which interest rates are low because the opportunity cost of holding durables is low in that period. Before the interest rate cut, demand is elevated due to expected capital gains on durables because the relative price of durables rises as the interest rate cut nears. After the interest rate cut, those households that accelerated their adjustments are no longer purchasing durables, which creates a reversal in demand.

The notable feature of the figure is that cutting the contemporaneous interest rate is much more effective at stimulating demand at $t=0$ than is cutting future interest rates. Figure 5 shows that a contemporaneous $1 \%$ cut is three times more effective than a $1 \%$ cut two years from now. This result stands in contrast to the standard three equation model, which predicts "perfect substitutability" between current and future interest changes for demand at $t=0$. This is shown by the opaque, dashed lines in Figure 5 . We simulate the three equation model assuming an intertemporal elasticity of substitution equal to $\hat{\sigma}^{-1}=2.46$, which implies that the interest rate cut at $t=0$ has the same output effect on impact as in the full model. Durable goods demand is the key source of difference between our model and the three equation model. If we modify our model to have only non-durable consumption and a larger intertemporal elasticity of substitution, the output response to forward guidance looks very similar to the three equation model because the model is then close to the incomplete-markets irrelevance case in Werning (2015). ${ }^{21}$

Forward guidance is a key unconventional policy tool that central banks have used at the ELB. Because our model implies forward guidance is less effective, a central bank facing an ELB is less able to offset negative shocks to aggregate demand. We illustrate the importance of lumpy durables for monetary policy ammunition ("policy space") with a simple calculation. By how much can the central bank raise output by reducing the real interest rate by 2.5 percentage points for four quarters? This experiment is motivated by current estimates of the nominal natural rate of interest around $2.5 \%$. Thus, we study a policy that cuts nominal rates to the zero lower bound while inflation expectations remain constant. The experiment implicitly assumes that the central bank can commit to a path for policy for four quarters but not longer than that. In response to this policy we find that current output rises by $4.8 \%$. For comparison, suppose that future interest reductions

\footnotetext{
${ }^{21}$ See Appendix Figure A.6.
} 


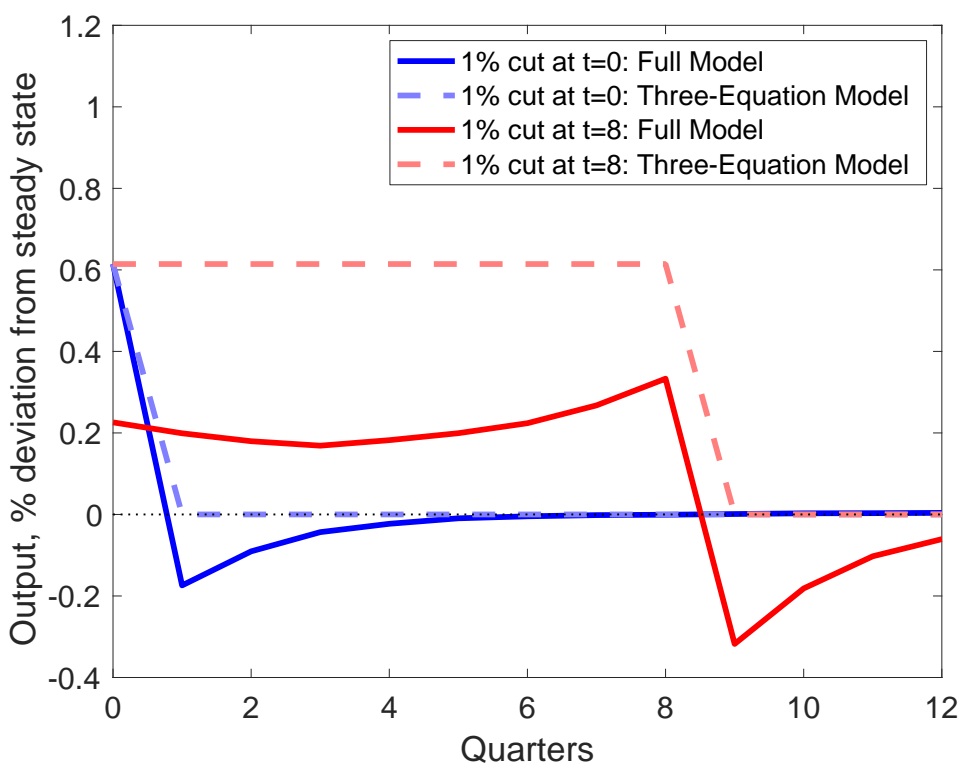

Figure 5: Output responses to real interest rate cuts of $1 \%$ (annualized) that last for one quarter at horizons of 0 and 8 quarters. Full model refers to our model with lumpy durables. Three equation model refers to the standard New Keynesian model, calibrated to yield the same impact effect on output for the contemporaneous interest rate cut. The simulation includes endogenous changes in aggregate income and the relative durable price. Perfect foresight transition paths.

were just as powerful as contemporaneous interest rate reductions as in the three equation New Keynesian model, then the central bank has $6.2 \%$ of policy space. So the imperfect substitution of future interest rates for current rates reduces policy space by 1.4 percentage points.

\subsection{Intertemporal Tradeoffs in Aggregate Demand Management}

In the three equation model, a history of low interest rates has no bearing on demand today. By contrast, this history is an important determinant of aggregate demand in the lumpy durable model.

To make this case, we fix a given path of interest rates from $t=0$ onward, and ask how output at $t=0$ depends on the history of interest rates? Figure 6 simulates a real interest rate path that lowers the real rate by one percentage point (annualized) for three quarters from $t=0$ to $t=2$. The figure shows two histories. The solid line shows the effect of this policy starting from steady state. The dashed line assumes that the economy has previously undergone two quarters of $-1 \%$ stimulus. We find that there is a substantial difference in output in $t=0$ under these two scenarios with output almost a percentage point higher in the scenario without a history of stimulus. This is because under a history of stimulus some of the households that were going to adjust during 


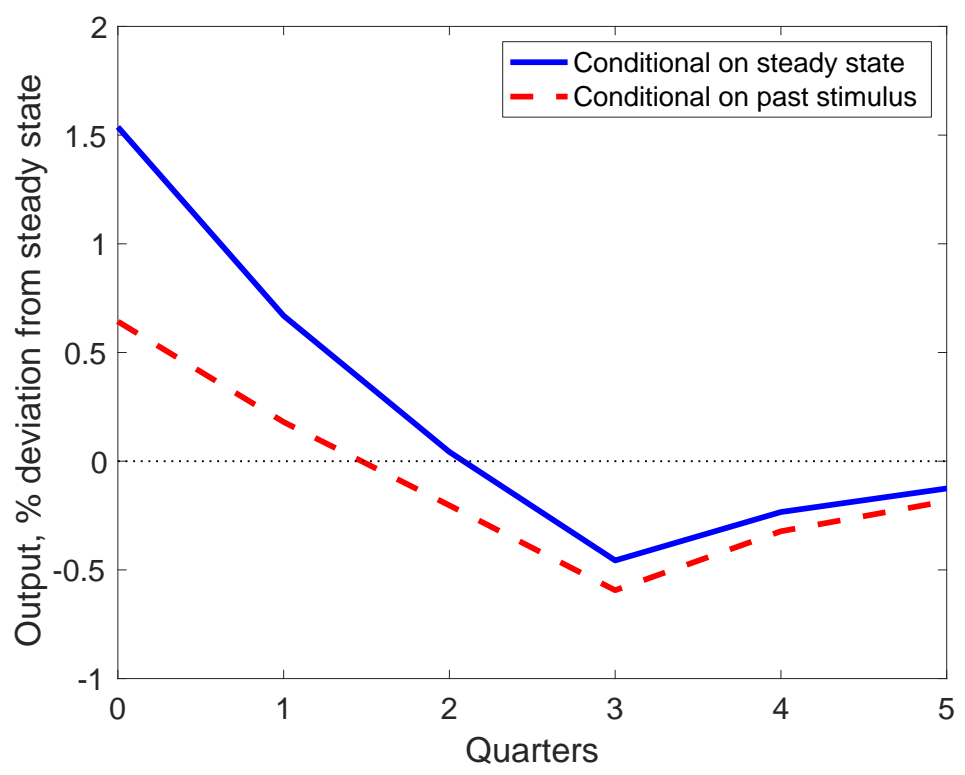

Figure 6: Output response for two different real interest rate paths. Both scenarios have a real interest rate 1 p.p. below steady state in periods $t=0$ to 2 . The scenario depicted by the dashed red line also had the real interest rate 1 p.p. below steady state in the two previous quarters. The scenario depicted by the solid blue line was previously in steady state. The simulation includes endogenous changes in aggregate income and the relative durable price. Perfect foresight transition paths.

periods 0 to 2 have already adjusted.

We repeat our policy space calculation to show how a history of stimulus affects policy space. Above we reported that cutting rates by $2.5 \%$ for four quarters increased output by $4.8 \%$. If the central bank had previously cut rates by $2.5 \%$ for four quarters, policy space falls to $3.3 \%{ }^{22}$ This result creates a dynamic trade-off for the central bank: if aggregate demand is low now, but expected to be even lower in the future, then the central bank may want hold off on interest rate cuts to maintain its policy space for when it is most needed. This trade-off is absent in the standard three equation model.

\subsection{Monetary Policy Loses Power in Recessions}

Policy space is particularly relevant in a recession caused by a short-fall of demand. However, the recession itself may directly reduce policy space by reducing households' willingness to hold more durables and thereby reducing the mass of households near the adjustment threshold. This

\footnotetext{
${ }^{22}$ Our policy space calculations assume a counter-factual in which real interest rates are constant both in the past and going forward.
} 
logic echoes Berger and Vavra (2015), who show state dependence of durable demand to a range of shocks, including interest rate shocks, in partial equilibrium. In this section we demonstrate the state dependent effects of monetary policy shocks when income and durable prices are determined in equilibrium. In the next section we allow for full general equilibrium with an endogenous real interest rate.

We induce a recession with a permanent reduction in TFP. With lower permanent income, households reduce their target level of durables and the economy has an overhang of durables resulting in a period of low aggregate demand. Because of sticky wages, the decline in aggregate demand creates a further decline in output beyond what is implied by the reduction in productivity. $^{23}$

As we further elaborate in Section 6, the size of the recession in durable expenditure is a key determinant of the mass of households near the adjustment threshold. We therefore choose the magnitude of the permanent income shock to match the $26.0 \%$ decline in real durable expenditure during the Great Recession. This target implies a permanent decline in $Z_{t}$ of $4.5 \%$. Figure 7 shows that output initially falls more than $5 \%$ below its new steady state level.

We illustrate the state dependence of monetary policy using our policy space experiment. That is, we assume the central bank reacts by promising four quarters of reducing the real interest rate by $2.5 \%$. Figure 8 shows that monetary policy is less powerful in the recession. The impact effect of the monetary stimulus is now $2.9 \%$ as compared to $4.8 \%$ in steady state. Thus, policy space is almost cut in half. The reason is that the overhang of durables in the recession implies that few households are near the adjustment threshold, and therefore few households are sensitive to monetary stimulus.

A history of stimulus reinforces this logic. If past monetary policy induced some individuals to pull forward their adjustments, then these marginal adjusters are missing when the recession hits. We quantify this effect by conditioning on a history in which the real interest rate was $-2.5 \%$ below steady state for the previous four quarters. Then, unexpectedly, the same permanent income shock occurs.

Past stimulus further reduces policy space for two reasons. First, the history of low interest rates reduces aggregate demand and makes the recession more severe. Second, by reducing the number

\footnotetext{
${ }^{23}$ Leahy and Zeira (2005) analyze this theoretical amplification channel and Dupor et al. (2018) argue that these forces gave rise the sharp collapse in the U.S. auto market during the Great Recession.
} 


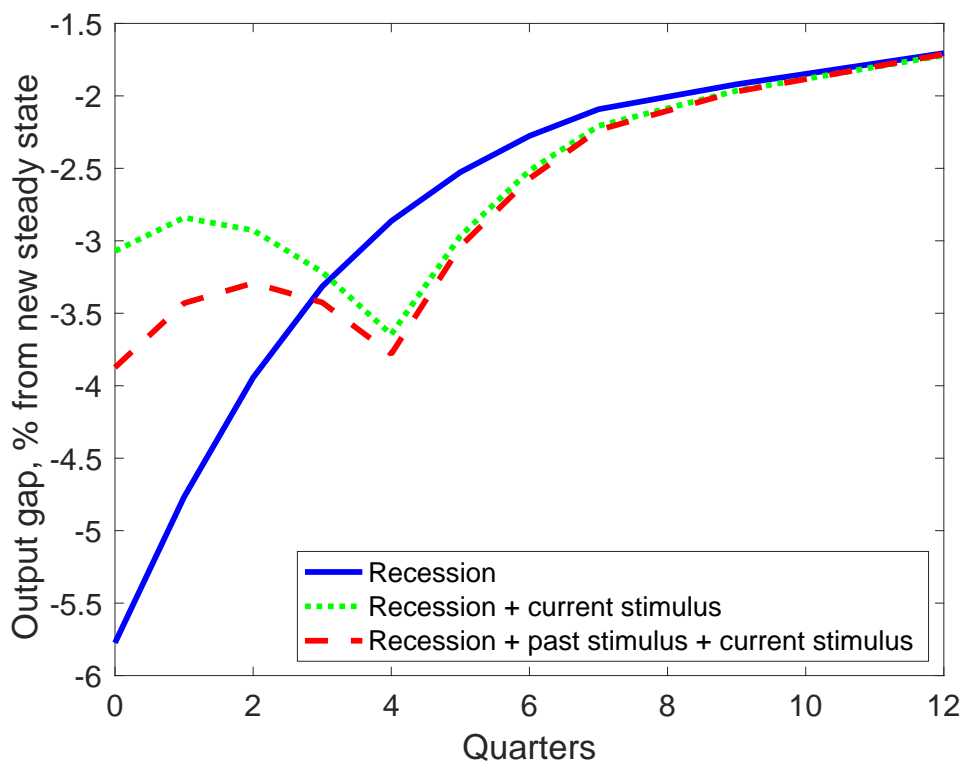

Figure 7: Output dynamics during a recession caused by a $4.5 \%$ permanent drop in TFP. The baseline scenario ("Recession") assumes no change in real interest rates. The other scenarios add current stimulus $(\Delta r=-2.5 \%$ for $t=0$ to $t=4)$ and past stimulus $(\Delta r=-2.5 \%$ for $t=-4$ to $t=0)$.

of households near the adjustment threshold it makes the new stimulus less effective. Together these effects reduce policy space to $2.0 \%$ relative to what would have occurred in the absence of previous monetary stimulus.

Our results imply that a lack of policy space is of particular concern when it is most needed, in a way that is missing from simple macroeconomic models. Furthermore, the intertemporal trade-offs facing a central bank give some credence to arguments about keeping the central bank's powder dry.

\section{General Equilibrium Attenuation of State Dependence}

In the previous section we demonstrated that the power of monetary policy is state dependent, but we assumed that the real interest rate was exogenous. There is a ongoing debate whether state dependence survives in lumpy investment models in general equilibrium (Khan and Thomas, 2008; Bachmann et al., 2013; Winberry, 2018; Koby and Wolf, 2018). We show that general equilibrium does not affect our state dependence results once we condition on the (observable) size of the recession. 


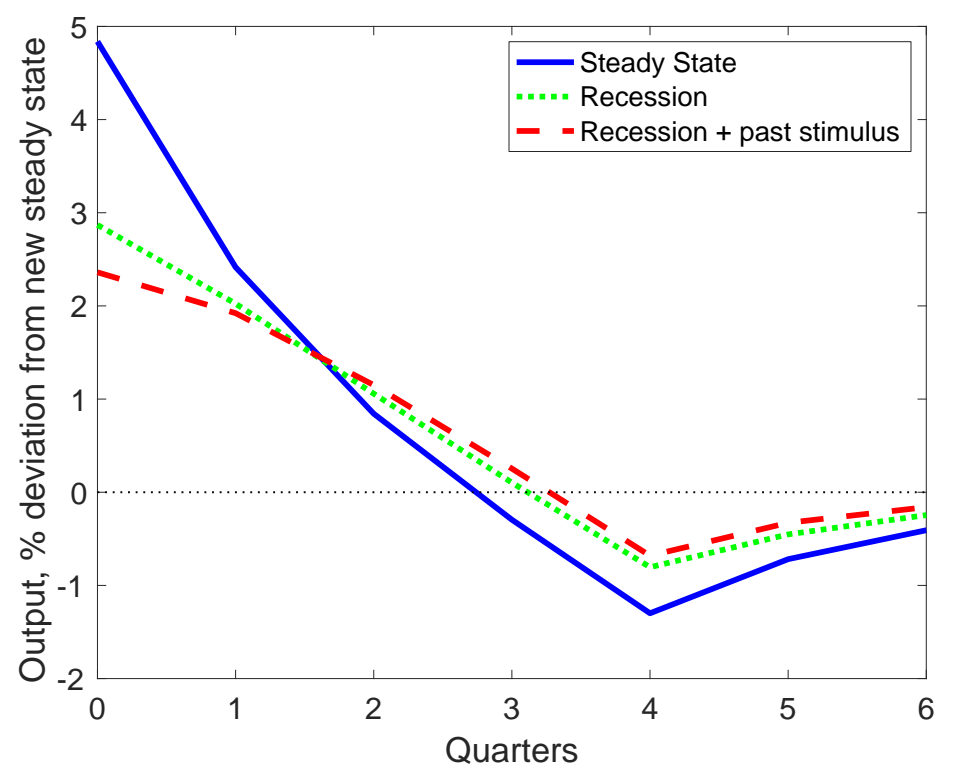

Figure 8: Change in output as a result of four quarters of $-2.5 \%$ change in real interest rates conditional on three scenarios: starting from steady state, during a recession caused by a permanent decline in TFP, and during the same recession when the economy had already received four quarters of monetary stimulus.

In order to understand how endogenous real interest rates affect the power of monetary policy in a recession, it is helpful to first be clear about how they affect the magnitude of the recession. In our simulated recession, the decline in TFP leads to an overhang of durables and a decline in durable demand below its new steady state level. The resulting decline in aggregate demand moves the economy along the Phillips curve to lower inflation and lower real interest rates through the monetary policy reaction function (13). The decline in real interest rates works to stabilize durable demand. The magnitude of this stabilizing effect is determined by the combination of the slope the Phillips curve, the coefficient on inflation in the monetary policy rule, and the interest elasticity of durable demand. In our full model the original $26 \%$ decline in durable expenditure is reduced to $18 \%$. This increases the power of our policy space stimulus to $3.8 \%$. With fixed real interest rates we found that the same stimulus increased output by $4.8 \%$ in steady state and $2.9 \%$ in the recession. As in Winberry (2018) and Koby and Wolf (2018), state dependence survives in general equilibrium due to our modest interest elasticity of durable demand, but it would appear that the degree of state dependence is diminished. However, the smaller recession in the simulation with endogenous real interest rates is inconsistent with the magnitude of the drop in durable demand in the Great Recession that motivated our original calculation. 


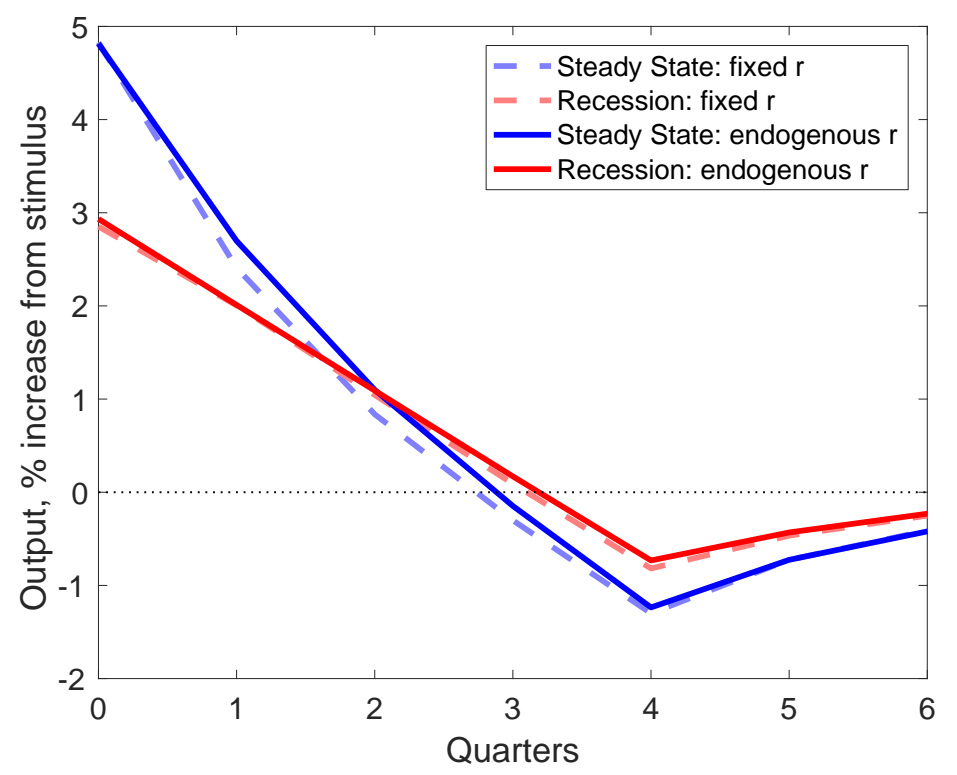

Figure 9: The effect of monetary stimulus in steady state and in a recession with and without endogenous interest rate movements. The experiment with a recession and endogenous interest rates assumes a larger TFP shock so that the equilibrium movement in durable expenditure is the same as in the fixed-interest rate experiment with a smaller TFP shock.

This observation leads us to consider a different experiment in which we fix the size of the recession across general equilibrium and partial equilibrium. We again target a $26 \%$ decline in durable expenditures, which requires a $6.6 \%$ decline in TFP with endogenous interest rates as compared to a $4.5 \%$ decline with exogenous real rates. We then perturb the economy with a $-2.5 \%$ shock to the interest rate rule for four quarters. ${ }^{24}$

In Figure 9 we see that the response of output to the monetary shock is almost identical regardless of whether real interest rates are fixed or endogenous. Therefore, general equilibrium forces do not affect state dependence once we condition on the size of the recession.

Figure 10 provides an explanation for this stark result. The figure shows the distribution of durable holdings relative to adjustment thresholds after one year in the absence of durable adjustments. $^{25}$ The fraction of households adjusting (extensive margin) is the CDF of the distribution

\footnotetext{
${ }^{24}$ While endogenous real interest rates reduce the size of a recession, they have little effect on the dynamics following monetary shocks in steady state. This reflects the fact that monetary shocks induce intertemporal substitution, so that positive output gaps today are largely offset by negative output gaps in the future. In the forward-looking Phillips curve this leads to only small changes in inflation, and thus only small endogenous real rate movements. This contrasts with the recession, in which the output gap is consistently negative and inflation consistently below target.

${ }^{25}$ We simulate the model from steady state for one year assuming no adjustments take place. We construct the distance from adjustment using the policy functions for each quarter over the first year and then average over the four quarters.
} 


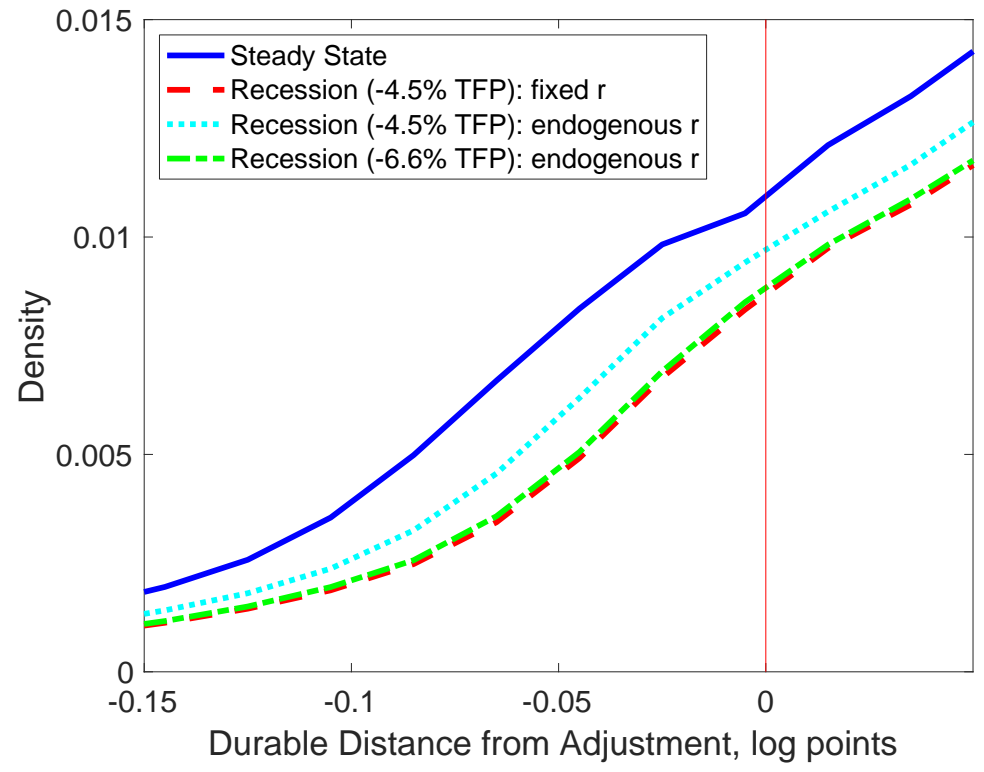

Figure 10: Distribution of durable holdings relative to adjustment thresholds after one year assuming no adjustments take place. The $\mathrm{x}$-axis denotes the log-point difference from the adjustment threshold, with negative values indicating that the adjustment threshold has been crossed. The four scenarios are (a) the steady state, (b) a $-4.5 \%$ permanent TFP shock causing a recession with a $26 \%$ drop in durable expenditure when the real rate is fixed, (c) a $-4.5 \%$ permanent TFP shock causing a recession with an $18 \%$ drop in durable expenditure when the real rate is endogenous, and (d) a $-6.6 \%$ permanent TFP shock causing a recession with a $26 \%$ drop in durable expenditure when the real rate is endogenous. 
at zero and the sensitivity of the extensive margin to stimulus is controlled by the density at zero. Shifts in this distribution therefore link changes in demand for durables from the extensive margin with changes in the sensitivity of the extensive margin to stimulus. Across simulations, shifts of the distribution reflect movements of the adjustment threshold. For example, the recession shock lowers the adjustment threshold, which pushes the distribution to the right. With an endogenous decline in real interest rates, the adjustment threshold increases, which pushes the distribution to the left. ${ }^{26}$ By choosing the shocks to target a particular size of the recession, the mass to the left of the threshold (i.e. the CDF at zero) is nearly the same regardless of whether real interest rates are fixed or endogenous. As a consequence, the densities of the two distributions at the adjustment threshold are nearly identical, which explains why state dependence is unaffected by general equilibrium in our experiment.

To summarize our argument, the degree of state dependence depends on how far the adjustment threshold moves and conditional on that the behavior of real interest rates is not important. In this sense, movements in the extensive margin act as a sufficient statistic for state dependence in our model. Ultimately, the data point to substantial fluctuations in the extensive margin over the business cycle (see Bachmann and Cooper, 2014; Dupor et al., 2018).

\section{Conclusion}

We investigate the implications of the micro-foundations of durable goods demand for monetary policy. In our heterogeneous agent model with fixed costs on durable adjustments, a key monetary transmission mechanism is to accelerate the timing of durable goods purchases. A first consequence of this channel is that the central bank faces an intertemporal trade-off for aggregate demand, as past stimulus reduces current demand. Second, the stimulative power of long-term interest rates is reduced, as households make a short-term decision of whether to adjust now or in the near future. Third, monetary policy is less powerful in a recession, with this state dependence unaffected by general equilibrium attenuation if one holds fixed the size of the recession.

In the face of an ELB constraint, our model implies that the central bank's ability to stabilize

\footnotetext{
${ }^{26}$ The degree to which general equilibrium shifts the distribution of durable gaps back towards the steady state distribution and attenuates state dependence depends on the interest elasticity of durable demand. This point is emphasized by House (2014), Winberry (2018), and Koby and Wolf (2018). In this sense, the interest rate elasticity is an important determinate of state dependence for a given shock as opposed to a given recession depth.
} 
the economy is substantially weaker than implied by a standard New Keynesian model. We have not conducted a welfare analysis or solved for optimal policy, but the model points to a risk management approach to monetary policy that preserves ammunition in light of downside risks to future aggregate demand. 


\section{A Computational Appendix}

We solve the model building on the routines available from Benjamin Moll's website http://www . princeton.edu/\%7Emoll/HACTproject.htm and described in Achdou et al. (2017).

\section{A.1 Steady state}

Define $k=a-\lambda d$ as the distance from the borrowing limit. Construct tensor grids over the state variables $(k, d, z)$. Then the steady state policy function is constructed as follows:

1. Start with an initial guess of the value function $v(k, d, z)$ and the value conditional on making an adjustment $v^{*}(k, d, z)$.

2. Solve for the optimal consumption and saving decisions when not adjusting. Compute $v_{k}$ both as a forward difference $v_{k}^{f}$ and as a backward difference $v_{k}^{b}$. At the boundaries of $v_{k}^{f}$ and $v_{k}^{b}$ impose that the drift of $k$ is zero. Invert $v_{k}(k, d, z)=U_{c}(c, d)$ to solve for $c^{f}(k, d, z)$ and $c^{b}(k, d, z)$, and the corresponding drift of $k, s^{f}(k, d, z)$ and $s^{b}(k, d, z)$. Finally, let $c^{0}(k, d, z)$ be the consumption consistent with zero drift. Pick among the candidates based on the following rule:

(a) If $s^{f}<0$ and $s^{b}<0$ pick $c^{b}, s^{b}$.

(b) If $s^{f}>0$ and $s^{b}>0$ pick $c^{f}, s^{f}$.

(c) If $s^{f}<0$ and $s^{b}>0$ pick $c^{0}, s^{0}$.

(d) If $s^{f}>0$ and $s^{b}<0$ pick the candidate that yields a larger value for the Hamiltonian.

Using the solution, compute the felicity function $u(c, d)$.

3. Construct the transition matrix $A$ based on the endogenous drifts of $k$ and the exogenous drifts and shocks to $d, z$. See Achdou et al. (2017) for details.

4. The HJB equation can now be written as $\min \left\{\rho v-u-A v, v-v^{*}\right\}=0$, and solved using an LCP solver for $v$. We use Yuval Tassa's solver http://www . mathworks . com/matlabcentral/ fileexchange/20952.

5. Compute optimal choice of $d^{\prime}$ conditional on adjusting and the corresponding $v^{*}=\max _{d^{\prime}} v\left(k^{\prime}, d^{\prime}, z\right)$, where $k^{\prime}=\lambda d^{\prime}+k-(\lambda+f) d$. 
6. Repeat steps 1-5 until convergence.

7. To obtain the steady state distribution, convert the policy functions for $k^{\prime}$ and $d^{\prime}$ conditional on an adjustment to index form. Fractions of an index determine the weights we assign to each index.

8. Create a matrix $C^{\text {noadj }}=A-\operatorname{diag}(\theta)$. Then set all the columns in $C^{\text {noadj }}$ that correspond to adjustment points to zero. Define $A^{\text {adj }}=A-C^{\text {noadj }}$. This matrix contains the mass at adjustment points that needs to be reallocated to the nodes of the optimal $k^{\prime}, d^{\prime}$. We assign this mass to the nodes surrounding $k^{\prime}, d^{\prime}$ based on the index fractions in the previous step. This yields a matrix of adjustments $C^{a d j}$. The transition matrix is then $C=C^{\text {noadj }}+C^{\text {adj }}$.

9. Solve $0=C g$ for the steady state distribution $g$.

\section{A.2 Impulse response functions}

1. Repeat steps 1-5, iterating backward from the terminal condition $v_{T}=v$. Each iteration reduces $t$ by $\mathrm{d} t$. Continue until $t=0$ is reached.

2. Repeat steps 7-8 for each period of the IRF. The initial distribution $g_{0}$ requires a modification if $p_{0} \neq 1$. The distribution of $k$ needs to shift since $k=a-\lambda p d$ and $a, d$ are fixed in that instant.

3. For each $t$, if the adjustment thresholds change, then all the mass in $g_{t}$ that is in the new adjustment region must be immediately shifted to its new location using the procedure in step 8. Call the new distribution $\hat{g}_{t}$. Then compute $g_{t+d t}=\hat{g}_{t}+C_{t} \hat{g}_{t} \mathrm{~d} t$. Repeat this step until $t=T$.

4. In general equilibrium, update the durable price and income, and repeat the previous steps 1-3 until convergence. For the case where the real rate is endogenous, compute the Jacobian with respect to the real rate of durables $r_{t}^{d}$ at each iteration step, and use the Newton method to update the real rate $r_{t}^{d}$. From $r_{t}^{d}=r_{t} \frac{p_{t+d t}}{p_{t}}$ calculate $\left\{r_{t}, p_{t}, Y_{t}\right\}_{0}^{T}$ using (13), (11), (12), the terminal conditions $r_{T}=\bar{r}, p_{T}=1, Y_{T}=1$, and using $Y_{t}=X_{t}+Y_{t}^{\text {smooth }}$, where $Y^{\text {smooth }}=c+G+\left(r^{b}-r\right) \int_{0}^{1} a_{i t} I_{a_{i t}<0} \mathrm{~d} i$ is the solution for the (smooth) non-durable components of aggregate demand from the previous iteration. 


\section{B Estimation}

The estimation strategy largely follows Berger and Vavra (2015). The details of the data selection and estimation algorithm below are meant to facilitate replication of our results.

\section{B.1 Data}

We use PSID data from 1999 through 2009.

\section{B.1.1 Variables}

Real non-durable consumption is nominal non-durable consumption in the PSID deflated by the BEA price index for non-durables (NIPA table 1.1.4). Nominal non-durable consumption is the sum of food expenditures, utility expenditures, home insurance, transportation expenditures, property taxes, health expenditures, child care expenditures, and education expenditures. We exclude any loan or lease payments from transportation expenditures to align the definition of non-durables with our model.

Real durable holdings are the sum of real house values and real vehicle values. Real house values are reported nominal house values deflated by the OFHEO national house price index. For renters we convert rent to a house value using the national house-to-rent ratio from Davis et al. (2008) available at http://www.aei.org/housing/land-price-indicators/. The PSID records the net wealth of up to three vehicles per household. We sum these values, add total vehicle debt (detailed below), and deflate the sum with the BEA price index for motor vehicles (NIPA table 1.2.4).

Real liquid asset holdings are the sum of cash and deposit holdings, stock holdings, and bond holdings, deflated by the non-durables price index.

We construct net real liquid assets by subtracting real debt from housing and vehicles. Mortgage debt is directly reported and we deflate it using the non-durables price index. We construct existing vehicle debt from the initial loan amount on all three cars and subtract the number of payments made times the average payment amount. In less than $1 \%$ of cases this results in a negative debt value, in which case we set vehicle debt to zero.

Housing adjustments come from either moving or a significant addition or repair. The PSID records the month and year of the most recent move since either the last interview (pre-2003) or 
since January two years ago. If a move is recorded and the move falls after the previous interview, then we code it as a housing adjustment for the current wave; otherwise it is an adjustment in the previous wave. When the move falls in the month of the interview we break the tie based on whether the interview was in the first or second half of the month. For significant additions and repairs we record them as housing adjustments in the wave that they are reported.

Car adjustments are set to one if any one of the three reported cars has been acquired since the previous wave. This is the case if the most recent car's acquisition date is after the previous wave's interview date, or (if there is insufficient information using the date) a new car has been acquired less than three years ago and it was not reported in the previous wave.

The sample weight is the household weight in the PSID.

\section{B.1.2 Sample selection}

We only keep head of households since the data is reported at the household level. We drop heads of households 21 and younger, as well as households present for fewer than 3 waves. This selection helps with the estimation of household fixed effects. We drop households with zero durable holdings, or those with missing information on any variable. We winsorize all variables at the $5^{\text {th }}$ and $95^{\text {th }}$ percentile.

\section{B.1.3 Household fixed effects}

We demean durable holdings by the households average durable holdings over the sample. This accounts for permanent differences in tastes for durables across households, which are not part of the model. We also divide non-durable consumption, liquid asset holdings, and real debt holdings by a household's average non-durable consumption over the sample. This helps account for permanent differences in income, which are again not part of the model.

\section{B.1.4 Consistency with national aggregates}

We divide all variables by average non-durable consumption in the sample. We then multiply each scaled variable (durables, liquid assets, debt) by a factor so that the sample average aligns with national aggregates from the fixed asset tables (durable-to-non-durable-consumption ratio) and the flow of funds (liquid-asset-to-non-durable-consumption and debt-to-non-durable-consumption). 
The rescaling is necessary because the PSID collects data for $72 \%$ of non-durable expenditures on average (Li et al., 2010). Further, households appear to overestimate the value of their vehicles (Czajka et al., 2003).

\section{B.2 Estimation Algorithm}

The steps of the algorithm are as follows:

1. Solve the model for a given intensity of match quality shocks $\theta$.

2. Forecast the probability of adjustment $P(a, d, y)$ for each initial state $(a, d, y)$ over the next two years. Also forecast the average non-durable consumption expenditure (including operating and maintenance costs) $\bar{c}$ for each initial state $(a, d, y)$ over the next two years. From the latter we obtain a steady-state distribution $G(a, d, \bar{c})$.

3. Regress the optimal durable stock $d^{*}$ in the model on $a, a^{2}, d, \bar{c}, d / \bar{c}$ weighted using the steadystate distribution. The vector of estimated coefficient is $\beta$.

4. Add measurement to the model variables $a, d, \bar{c}$ using three independent Gaussian quadratures, one for each variable. This yields a new distribution $\hat{G}(a, d, \bar{c})$ which includes measurement error. Note that the adjustment probabilities are based on the true underlying $G(a, d, \bar{c})$.

5. Compute gaps $\omega=d^{*}-d$ for each point in the distribution $\hat{G}$. Integrating over $\omega$ using $\hat{G}$ yields the pdf $f(\omega)$ in the model. Similarly integrating the probability of adjustment $P(a, d, y)$ over $\omega$ using $\hat{G}$ yields the hazard rate $h(\omega)$ in the model.

6. In the data combine reported $a, d, \bar{c}$ and our estimates $\beta$ to predict $d^{*}$ and the durable gap $\omega=d^{*}-d$. Use the sample weights to compute $f(\omega)$ and the adjustment hazard $h(\omega)$.

7. Compute loss function $L=\sum_{\omega} w(\omega)\left[\left|f^{\text {model }}(\omega)-f^{\text {data }}(\omega)\right|+\left|h^{\text {model }}(\omega)-h^{\text {data }}(\omega)\right|\right]$ where the weight is $w(\omega)=\frac{1}{4}\left(f^{\text {model }}(\omega)+f^{\text {data }}(\omega)\right)\left(h^{\text {model }}(\omega)+h^{\text {data }}(\omega)\right)$. This weighting function attaches more weight to bins the greater the fraction of adjustments accounted for by that bin. Conversely, we attach little weight to regions in which both model and data predict few adjustments. 
8. Repeat steps 4,5, and 7 using a range of values for the standard deviation of the measurement error. Then pick the value that results in the smallest loss in 7 .

9. Repeat steps 1-8 using a range of values for $\theta$. Pick the $\theta$ with the smallest loss in 8 .

10. To construct standard errors, sample 1000 new datasets with replacement from the original dataset. Repeat steps 6 and 7 for each dataset, record the loss-minimizing value for $\theta$ and the associated density and hazard function from both data and model.

\section{Data Appendix}

\section{C.1 Variables for Impulse Response Functions}

In this section we detail how we construct the variables for the empirical impulse response functions to monetary policy shocks in figures 2 and 3 of section 3 .

The base series the set of variables in Table 4, which we download from the St Louis FRED database.

To construct real durable and non-durable expenditure, we first construct their respective price indices. The problem is one where we have two components of nominal expenditure $y_{t}=x_{1 t}+$ $x_{2 t}$ (e.g., durable expenditure equals consumer durables plus residential investment), and their respective price indices $p_{1 t}$ and $p_{2 t}$. We want to construct the price index $p_{t}$ for $y_{t}$. We first construct average annual nominal expenditure $y_{t}^{a}=\frac{1}{4} \sum_{t \in \text { year=a }} y_{t}$, and the shares of the components, $s_{1 t}^{a}=$

$\frac{x_{1 t}^{a}}{y_{t}^{a}}$ and $s_{2 t}^{a}=\frac{x_{2 t}^{a}}{y_{t}^{a}}$. We regress one of the annual shares on an annual quadratic time trend, create the predicted values $\bar{s}_{1 t}^{a}$, and use it as a weight, $p_{t}=\bar{s}_{1 t}^{a} p_{1 t}+\left(1-\bar{s}_{1 t}^{a}\right) p_{1 t}$. Real expenditure is then calculated as $y_{t} / p_{t}$. We convert all real expenditure to per capita by dividing by population.

We follow this procedure for both durables (consumer durables plus residential investment) and non-durables (consumer non-durables plus services net of housing).

For the price series of residential investment and consumer services we make specific modifications. We separate residential investment into investment into new structures and other residential investment. For investment into new structures we use the FHFA national house price index to capture changes in the price of land as well as the price of the new structure. For other residential investment we use that respective price index from the BEA. The weights are based on nominal expenditures in new residential structures and other residential investment and calculated as above. 


\begin{tabular}{|c|c|}
\hline Variable Name & FRED Series Code \\
\hline Population & B230RC0Q173SBEA \\
\hline Income (GDP) & GDPC1 \\
\hline Federal Funds Rate & FEDFUNDS \\
\hline Consumer Durable Expenditure & PCDG \\
\hline Residential Investment & PRFI \\
\hline Consumer Non-durable Expenditure & PCEND \\
\hline Consumer Service Expenditure & PCES \\
\hline Consumer Housing Services Expenditure & DHSGRC0 \\
\hline Durable Price Index & DDURRD3Q086SBEA \\
\hline Residential Investment Price Index & B011RG3Q086SBEA \\
\hline Non-durable Price Index & DNDGRG3M086SBEA \\
\hline Services Price Index & DSERRG3M086SBEA \\
\hline Services Price Index: Housing & DHUTRG3Q086SBEA \\
\hline Consumer Expenditure: Motor Vehicles & DMOTRC1Q027SBEA \\
\hline Motor Vehicles Price Index & DMOTRG3Q086SBEA \\
\hline House Price Index & USSTHPI \\
\hline Residential Investment: Permanent Site & A943RC1Q027SBEA \\
\hline Residential Investment: Other & A863RC1Q027SBEA \\
\hline Residential Investment Price Index: Other & A863RG3Q086SBEA \\
\hline
\end{tabular}

Table 4: Variable names and FRED series code.

For consumption of services we remove housing services because housing services in the model are obtained from $h_{t}$ and not counted in $c_{t}$. To do so we follow the same procedure as above for the housing and non-housing component of services. But rather than adding, we subtract the housing component, $y_{t}=x_{2 t}-x_{1 t}$, and the price index is calculated as $p_{t}=\left(p_{2 t}-\bar{s}_{1 t}^{a} p_{1 t}\right) /\left(1-\bar{s}_{1 t}^{a}\right)$.

The relative price series for durables is the price of durables divided by the price of non-durables and services. The real interest rate is defined in terms of non-durables. It is the federal funds rate net of realized non-durable inflation from this quarter to the next quarter. 


\section{C.2 PSID: Housing Adjustment Probability}

This section details how we construct the time series for the probability of housing adjustment using the Panel Survey of Income Dynamics (PSID). We use these data to measure the extensive margin response of housing to monetary shocks in table 2 of section 3.

\section{C.2.1 Sample}

We keep only people who are heads of household and those who are in the Survey Research Center (SRC) sample. We only use PSID data from 1969-1997 when the survey frequency is annual.

\section{C.2.2 Adjustment Series}

We use the moved since spring series to create a record of adjustments. If moved since spring is true, we record an adjustment for that year. If moved since spring is false, we record no adjustment for that year. If the value is missing, we stop counting until the next time an adjustment is recorded, then count from there.

Tenure Status Tenure status refers to knowing what type of housing (rent or own). We use

the series from the PSID labeled own/rent or what. There are also values for "other" or "not applicable." If the values are "other" or "not applicable" we mark the tenure status as missing.

To align with Bachmann and Cooper (2014), we set values to missing if the observation does not have a tenure status or is lag does not have a tenure status. For example, if their observation is in the year 1992, we will set the adjustment series to missing if we do not know whether the head of household was owning or renting in either 1991 or 1992.

\section{C.2.3 Weights}

To weight observations in the regression, we take the mean of the family weight provided associated with the head of household across all periods for which we have year to year housing adjustments (1969-1997).

\section{C.2.4 Time Series}

We create a time series of the probability of adjustment by aggregating the panel using the family weight. 


\section{C.3 CEX: Car acquisition probability}

We use the consumer expenditure (CEX) survey from 1980-2017 to construct a quarterly time series of the probability of a household acquiring a car or truck (used or new). We use this time series in table 2 to measure the extensive margin response of auto purchases to monetary policy shocks.

We download the pre-compiled files from the BLS for 1996 onwards. The CEX files before 1996 are from ICPSR. We only use the family and expenditure files. We clean the micro-data files following Coibion et al. (2017). We drop households with negative elderly expenditure, zero total expenditure, or zero food consumption. We sum expenditures that occur in the same month but are reported in different interviews as recommended by the BLS. We drop households that report more than three monthly expenditures per interview, since it is difficult to allocate the additional monthly expenditures. We also drop interviews with fewer than three months of data.

In the expenditure files we sum the UCC codes 450110 (new cars), 450210 (new trucks), 460110 (used cars), 460901 (used trucks). All expenditure series are net of trade-in value. This definition aligns with the BEA definition of motor vehicle expenditure. Using the household weights, total motor vehicle expenditure implies by the CEX tracks BEA personal consumption motor vehicle expenditure very well (Figure A.1).

We construct the probability of adjustment by setting an indicator equal to 1 whenever a household's motor vehicle expenditures are positive, and aggregating the indicator using household weights.

\section{C.4 CPS: Reasons for moving}

Reasons for moving are from the March 2001 CPS supplement. We classify these reasons according to whether they broadly fall into life-cycle changes, which more closely correspond to our unmodeled match-quality shocks, and sS-band reasons, which capture the traditional adjustments in fixed cost model from a depreciating durable stock.

We classify wanting a new/better home and cheaper housing is suggestive of durable holdings away from target and price-sensitivity in line with the traditional fixed cost model. These account for roughly a quarter of all adjustments, in line with our calibration of match-quality shocks. Changes in marital status or job-related moving more closely align with life-cycle changes that are less directly tied to interest rates. These account for roughly half of all transitions. The remaining 


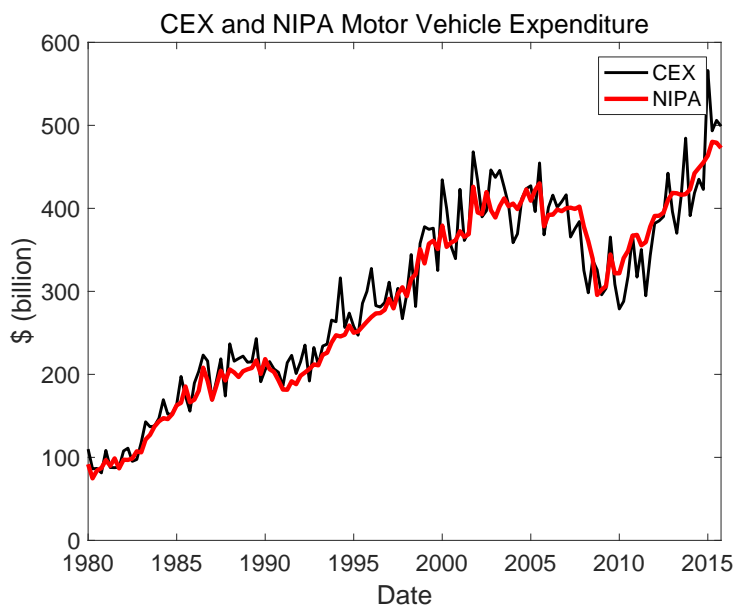

Figure A.1: Household motor vehicle expenditure from the personal consumption expenditure table in NIPA, and extrapolated from CEX micro-data based on NIPA definitions based on survey weights.

quarter of moves are obviously classifiable in either category.

\section{Additional Results}

\section{D.1 Price levels: non-durables and durables}

See Figure A.2.

\section{D.2 Real rate in terms of durables}

See Figure A.3.

\section{D.3 Other relative prices: residential investment and cars}

See Figure A.4.

\section{D.4 Nominal interest rate responses}

Figure A.5 shows the nominal interest rate requires to implement the experiment in which the real interest rate falls by $1 \%$ at a horizon of 8 quarters. 

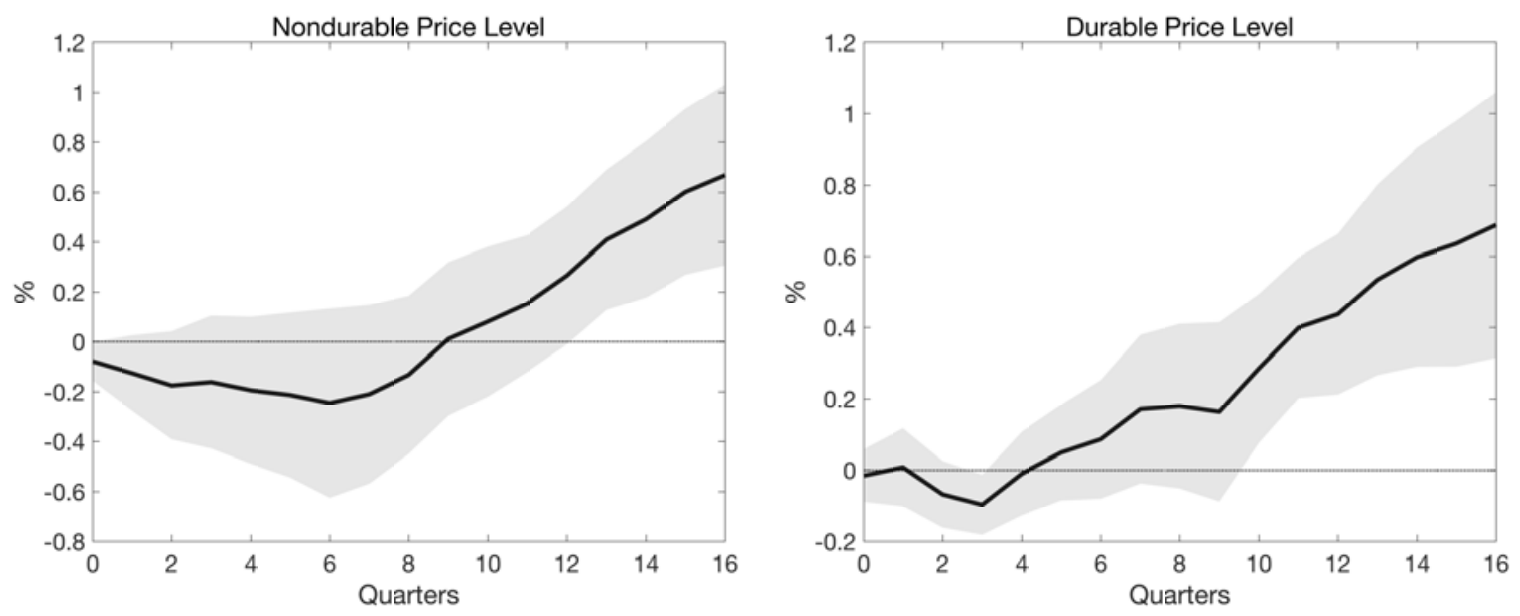

Figure A.2: Impulse response function for the level of non-durable prices (left panel) and durable prices (right panel) following a Romer and Romer (2004) monetary policy shock. Based on the regression (9).

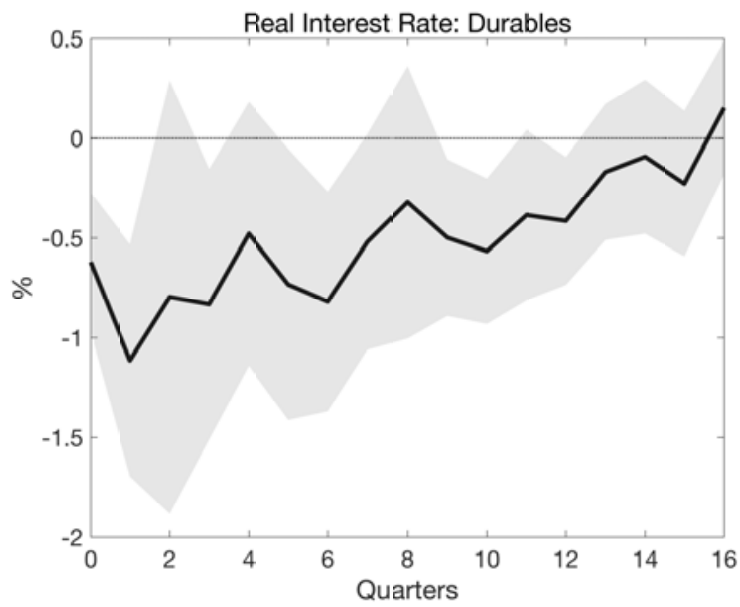

Figure A.3: Impulse response function for the real interest rate in terms of durables following a Romer and Romer (2004) monetary policy shock. Based on the regression (9). 

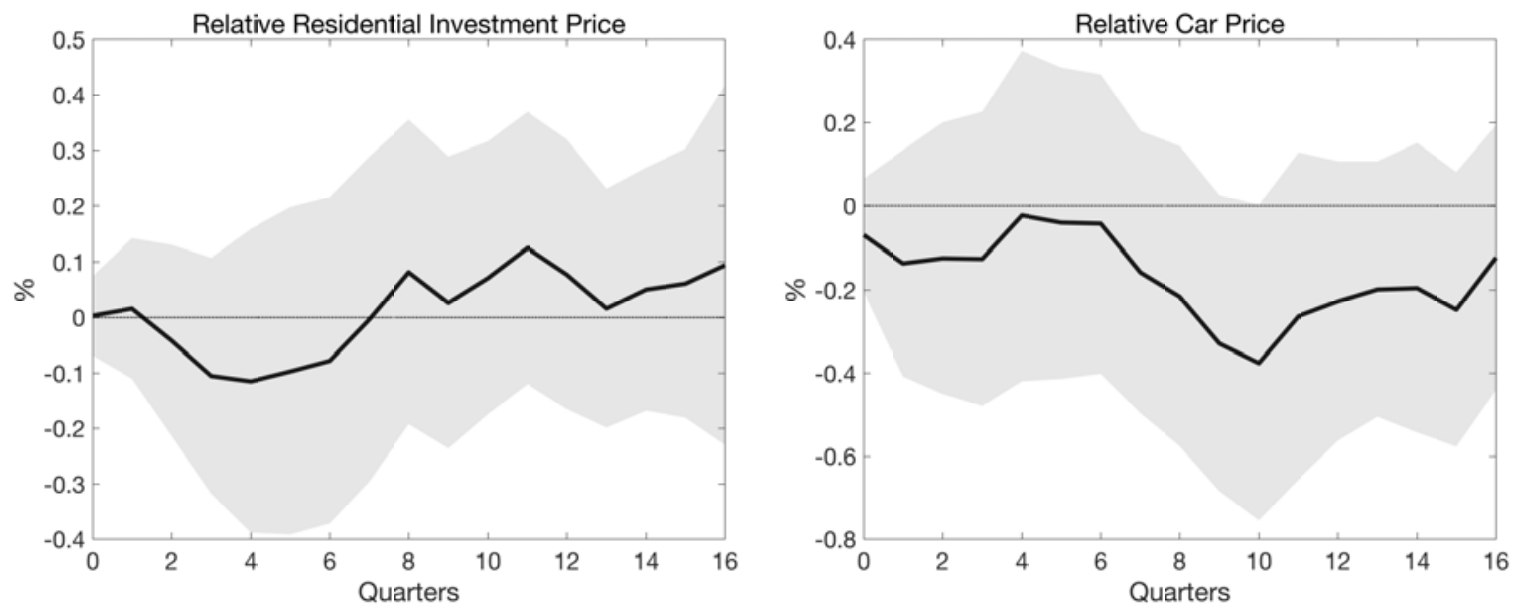

Figure A.4: Impulse response function for the price of residential investment relative to the price of non-durables and services (left panel) and the price of motor vehicles relative to the price of nondurables and services (right panel) following a Romer and Romer (2004) monetary policy shock. Based on the regression (9).

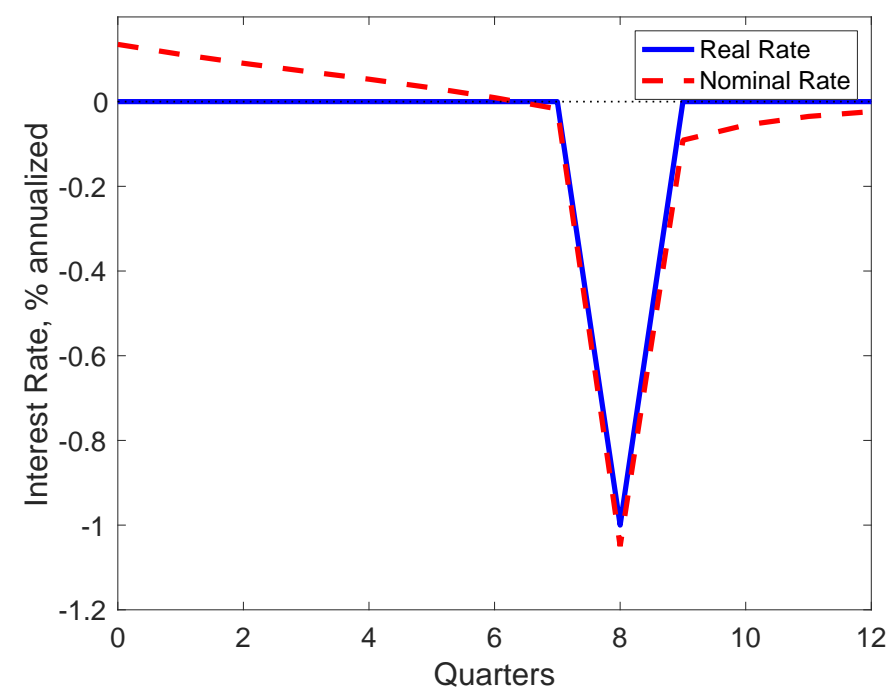

Figure A.5: Response of real and nominal interest rates to a change in future interest rates. 
Table 5: What was ... main reason for moving?

\begin{tabular}{lccc}
\hline & Frequency & sS-Band & Life-cycle \\
Change in marital status & $0.84 \%$ & No & Yes \\
To establish own household & $1.06 \%$ & No & Yes \\
Other family reason & $1.92 \%$ & No & Yes \\
New job or job transfer & $1.45 \%$ & No & Yes \\
To look for work or lost job & $0.27 \%$ & No & Yes \\
To be closer to work & $0.44 \%$ & $?$ & $?$ \\
Retired & $0.08 \%$ & No & Yes \\
Other job-related reason & $0.16 \%$ & No & Yes \\
Wanted to own home, not rent & $1.41 \%$ & $?$ & $?$ \\
Wanted new or better house & $2.47 \%$ & Yes & No \\
Wanted better neighborhood & $0.55 \%$ & $?$ & $?$ \\
Cheaper housing & $0.76 \%$ & Yes & No \\
Other housing reason & $1.52 \%$ & $?$ & $?$ \\
Attend/leave college & $0.43 \%$ & No & Yes \\
Change of climate & $0.08 \%$ & No & Yes \\
Health reasons & $0.19 \%$ & No & Yes \\
Total & $13.64 \%$ & $3.23 \%$ & $6.48 \%$
\end{tabular}

\section{D.5 Forward Guidance in Non-Durables Model}

Figure A.6 shows the forward guidance experiment in a version of our model that omits durable goods.

\section{D.6 General equilibrium attenuation of effects of past stimulus}

The dashed opaque lines in Figure A.7 plot the original experiment in Section 5.2, in which we compare a real rate path $1 \%$ below steady state for three quarters starting either in steady state or continuing from two previous quarters of low real interest rates. The two solid lines repeat these experiments as $-1 \%$ shocks to the interest rate rule, and allowing for the real interest rate to respond endogenously to inflation. The main takeaway is that the outcomes remain very similar to the 


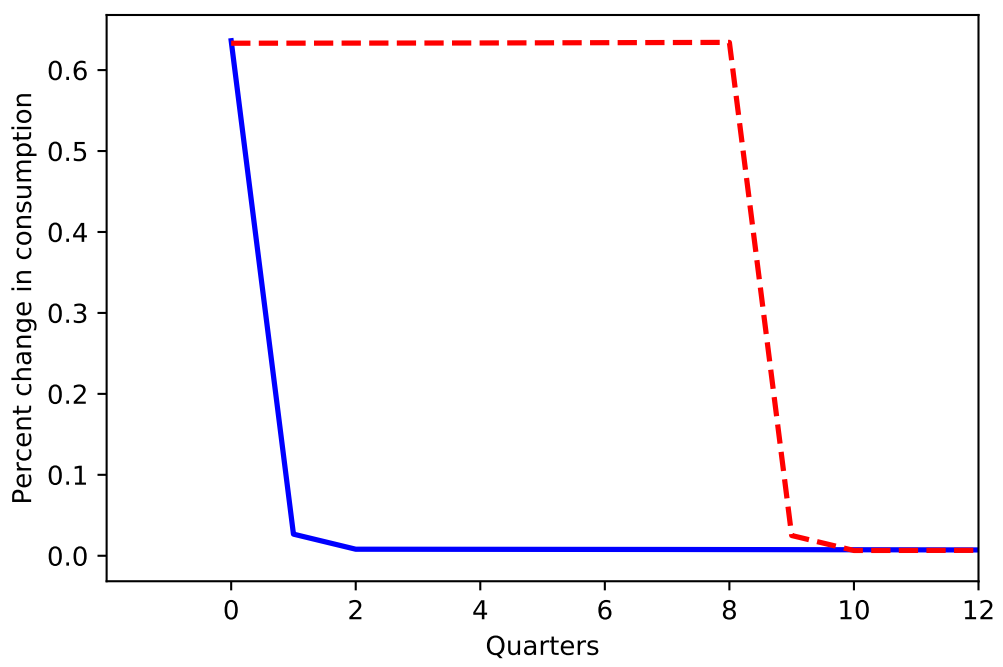

Figure A.6: Response of aggregate consumption to $1 \%$ interest rate cut at dates 0 and 8 in model with only non-durable consumption.

experiment with exogenous real interest rates, which already allowed for endogenous relative price movements. Previous stimulus implies that fewer households today are crossing the adjustment threshold, which reduces aggregate demand.

The interest elasticity of durable demand is important to these results. Recall that past stimulus creates a drag on demand because some households have already made their durable adjustments in response to the previous stimulus. As explained by House (2014), with a high interest elasticity of durable demand the existing distribution of durable holdings will have little effect on equilibrium expenditure because small changes in prices will stabilize durable demand. That logic is not nearly as powerful in our model as in the fixed-cost model because of the lower interest elasticity of durable demand.

\section{E Details of the General Equilibrium Model}

\section{E.1 The Labor Market}

The labor demand curve of each labor type $j$ is,

$$
l_{j t}=L_{t}\left(\frac{W_{j t}}{W_{t}}\right)^{-\varphi}
$$




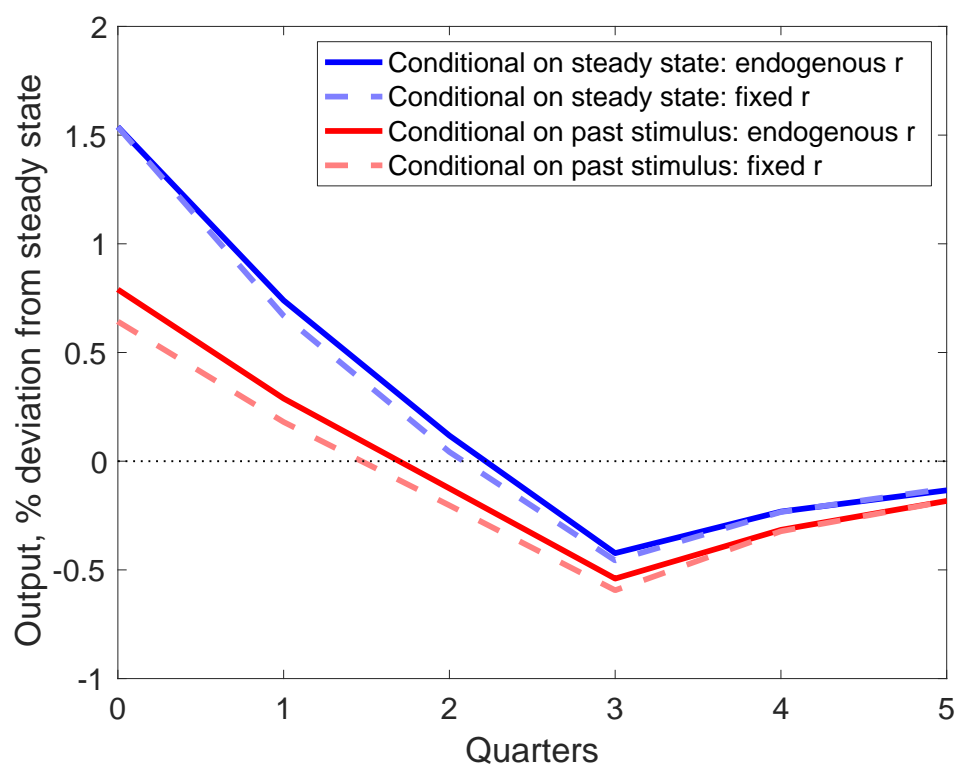

Figure A.7: The effect of past stimulus with endogenous real interest rates (solid lines) and with fixed real interest rates (dashed lines, see Figure 6 for description). The endogenous interest rates paths are generated by a $-1 \%$ shock to the monetary policy rule for periods $t=0$ to 2 . The figure shows two scenarios: starting from steady state and with a history of two quarters of $-1 \%$ stimulus.

so that the aggregate wage equal,

$$
W_{t}=\left(\int_{0}^{1} W_{j t}^{1-\varphi} d j\right)^{\frac{1}{1-\varphi}}
$$

The objective of the union is therefore,

$$
\max _{\left\{\mu_{j t}\right\}} \int_{t=0}^{\infty} e^{-\rho t} \int_{0}^{1}\left[u_{c}\left(c_{i t}, d_{i t}\right) \frac{W_{j t}}{P_{t}} l_{j t}-\bar{u}_{c, t} v\left(l_{j t}\right)-\frac{\Psi}{2} \bar{u}_{c, t} L_{t} \mu_{j t}^{2}\right] \mathrm{d} i \mathrm{~d} t
$$

subject to

$$
\begin{aligned}
\operatorname{dln} W_{j t} & =\mu_{j t} \mathrm{~d} t \\
l_{j t} & =L_{t}\left(\frac{W_{j t}}{W_{t}}\right)^{-\varphi}
\end{aligned}
$$

The first order conditions of the union are,

$$
\begin{aligned}
\lambda_{j t} & =\Psi \mu_{j t} \bar{u}_{c, t} L_{t} \\
\mathrm{~d} \lambda_{j t}-\rho \lambda_{j t} \mathrm{~d} t & =-(1-\varphi) \bar{u}_{c, t}\left(\frac{W_{j t}}{P_{t}}\right)^{1-\varphi}\left(\frac{W_{t}}{P_{t}}\right)^{\varphi} L_{t} \mathrm{~d} t-\varphi L_{t}\left(\frac{W_{j t}}{W_{t}}\right)^{-\varphi} \bar{u}_{c, t} v_{L}\left(l_{j t}\right) \mathrm{d} t
\end{aligned}
$$


Imposing symmetry and market clearing

$$
\begin{aligned}
\Psi \mu_{t} \bar{u}_{c, t} \frac{Y_{t}}{Z_{t}} & =\lambda_{t} \\
\mathrm{~d} \lambda_{t}-\rho \lambda_{t} \mathrm{~d} t & =-(1-\varphi) \bar{u}_{c, t} \frac{Y_{t}}{Z_{t}} \mathrm{~d} t-\varphi \bar{u}_{c, t} \frac{Y_{t}}{Z_{t}} v_{L}\left(\frac{Y_{t}}{Z_{t}}\right) \mathrm{d} t \\
\pi_{t} & =\mu_{t}
\end{aligned}
$$

The non-linear Phillips curve is then,

$$
\mathrm{d} \pi_{t}=\left[\rho-\frac{\mathrm{d} \bar{u}_{c, t}}{\bar{u}_{c, t}}-\frac{\mathrm{d} Y_{t}}{Y_{t}}+\frac{\mathrm{d} Z_{t}}{Z_{t}}\right] \pi_{t} \mathrm{~d} t-\frac{\varphi-1}{\Psi}\left[\frac{\varphi}{\varphi-1} v_{L}\left(\frac{Y_{t}}{Z_{t}}\right)-1\right] \mathrm{d} t
$$

and log-linearized around the zero inflation steady-state

$$
\mathrm{d} \pi_{t}=\rho \pi_{t} \mathrm{~d} t-\frac{\varphi}{\Psi} \eta\left(\frac{Y_{t}-\bar{Y}}{\bar{Y}}-\frac{Z_{t}-\bar{Z}}{\bar{Z}}\right) \mathrm{d} t
$$

where $\frac{1}{\eta}$ is the Frisch elasticity. Letting $\kappa=\frac{\varphi \eta}{\Psi}$ gives (11).

\section{E.2 Market Clearing}

Non-durables market clearing:

$$
Y_{t}=\int_{0}^{1} c_{i t} \mathrm{~d} i+M_{t}+G_{t}+\left(r^{b}-r\right) \int_{0}^{1} a_{i t} I_{\left(a_{i t}<0\right)} \mathrm{d} i .
$$

Durable goods market clearing:

$$
X_{t}=\int_{0}^{1}\left(\frac{\mathrm{d} d_{i t}}{\mathrm{~d} t}-\delta d_{i t}\right) \mathrm{d} i+f \int_{0}^{1} I_{d_{i t}^{\prime} \neq d_{i t}} d_{i t}+\nu \int_{0}^{1} d_{i t} \mathrm{~d} i .
$$

Bond market clearing:

$$
\int_{0}^{1} a_{i t} \mathrm{~d} i=A_{t}
$$




\section{References}

Achdou, Y., Han, J., Lasry, J.-M., Lions, P.-L., and Moll, B. (2017). Income and wealth distribution in macroeconomics: A continuous-time approach. Technical report, National Bureau of Economic Research.

Albouy, D., Ehrlich, G., and Liu, Y. (2016). Housing demand, cost-of-living inequality, and the affordability crisis. Technical report, National Bureau of Economic Research.

Alvarez, F., Le Bihan, H., and Lippi, F. (2016). The real effects of monetary shocks in sticky price models: A sufficient statistic approach. American Economic Review, 106(10):2817-51.

Angeletos, G.-M. and Lian, C. (2018). Forward guidance without common knowledge. American Economic Review, 108(9):2477-2512.

Auclert, A. (2019). Monetary policy and the redistribution channel. American Economic Review, 109(6):2333-67.

Bachmann, R., Caballero, R. J., and Engel, E. M. (2013). Aggregate implications of lumpy investment: new evidence and a dsge model. American Economic Journal: Macroeconomics, $5(4): 29-67$.

Bachmann, R. and Cooper, D. (2014). The ins and arounds in the us housing market. Working paper.

Baker, S. R., Kueng, L., McGranahan, L., and Melzer, B. T. (2019). Do household finances constrain unconventional fiscal policy? Tax Policy and the Economy, 33(1):1-32.

Barsky, R., House, C. L., Boehm, C., and Kimball, M. S. (2016). Monetary policy and durable goods. Working paper.

Barsky, R. B., House, C. L., and Kimball, M. S. (2007). Sticky-price models and durable goods. American Economic Review, 97(3):984-998.

Berger, D. and Vavra, J. (2015). Consumption dynamics during recessions. Econometrica, 83(1):101-154.

Berger, D. W., Milbradt, K., Tourre, F., and Vavra, J. (2018). Mortgage prepayment and pathdependent effects of monetary policy. Technical report, National Bureau of Economic Research.

Carlstrom, C. T., Fuerst, T. S., and Paustian, M. (2015). Inflation and output in new keynesian models with a transient interest rate peg. Journal of Monetary Economics, 76:230-243.

Coibion, O., Gorodnichenko, Y., Kueng, L., and Silvia, J. (2017). Innocent bystanders? monetary policy and inequality. Journal of Monetary Economics, 88:70-89.

Czajka, J. L., Jacobson, J. E., and Cody, S. (2003). Survey estimates of wealth: A comparative analysis and review of the survey of income and program participation. Soc. Sec. Bull., 65:63.

Davidoff, T. and Yoshida, J. (2013). Estimating consumption substitution between housing and non-housing goods using macro data. Technical report, Working paper.

Davis, M. A. and Heathcote, J. (2007). The price and quantity of residential land in the united states. Journal of Monetary Economics, 54(8):2595-2620.

Davis, M. A., Lehnert, A., and Martin, R. F. (2008). The rent-price ratio for the aggregate stock of owner-occupied housing. Review of Income and Wealth, 54(2):279-284. 
Davis, M. A. and Ortalo-Magné, F. (2011). Household expenditures, wages, rents. Review of Economic Dynamics, 14(2):248-261.

Del Negro, M., Giannoni, M. P., and Patterson, C. (2015). The forward guidance puzzle. Working paper.

Dupor, B., Li, R., Mehkari, M., and Tsai, Y.-C. (2018). The 2008 us auto market collapse. FRB St. Louis Working Paper.

Eggertsson, G. B. and Woodford, M. (2003). The zero bound on interest rates and optimal monetary policy. Brookings Papers on Economic Activity, 2003(1):139-211.

Eichenbaum, M., Rebelo, S., and Wong, A. (2018). State dependent effects of monetary policy: The refinancing channel. Technical report, National Bureau of Economic Research.

Erceg, C. J., Henderson, D. W., and Levin, A. T. (2000). Optimal monetary policy with staggered wage and price contracts. Journal of monetary Economics, 46(2):281-313.

Farhi, E. and Werning, I. (2017). Monetary policy, bounded rationality, and incomplete markets. Technical report, National Bureau of Economic Research.

Floden, M. and Lindé, J. (2001). Idiosyncratic risk in the united states and sweden: Is there a role for government insurance? Review of Economic dynamics, 4(2):406-437.

Gabaix, X. (2016). A behavioral new keynesian model. Technical report, National Bureau of Economic Research.

Gali, J. (2008). Monetary Policy, Inflation, and the Business Cycle. Princeton University Press, Princeton, NJ.

Golosov, M. and Lucas, R. E. (2007). Menu costs and phillips curves. Journal of Political Economy, 115(2):171-199.

Goolsbee, A. (1998). Investment Tax Incentives, Prices, and the Supply of Capital Goods*. The Quarterly Journal of Economics, 113(1):121-148.

Gornemann, N., Kuester, K., and Nakajima, M. (2016). Doves for the rich, hawks for the poor? distributional consequences of monetary policy. CEPR Discussion Paper No. DP11233.

Guerrieri, V. and Lorenzoni, G. (2017). Credit crises, precautionary savings, and the liquidity trap. The Quarterly Journal of Economics, 132(3):1427-1467.

House, C. L. (2014). Fixed costs and long-lived investments. Journal of Monetary Economics, 68:86-100.

House, C. L. and Shapiro, M. D. (2008). Temporary investment tax incentives: Theory with evidence from bonus depreciation. American Economic Review, 98(3):737-68.

Kaplan, G., Moll, B., and Violante, G. L. (2018). Monetary policy according to hank. American Economic Review, 108(3):697-743.

Khan, A. and Thomas, J. K. (2008). Idiosyncratic shocks and the role of nonconvexities in plant and aggregate investment dynamics. Econometrica, 76(2):395-436.

Koby, Y. and Wolf, C. (2018). Understanding investment stimulus: From micro data to macro outcomes. Working paper. 
Leahy, J. V. and Zeira, J. (2005). The Timing of Purchases and Aggregate Fluctuations. The Review of Economic Studies, 72(4):1127-1151.

Li, G., Schoeni, R. F., Danziger, S., and Charles, K. K. (2010). New expenditure data in the psid: Comparisons with the ce. Monthly Labor Review, 133(2):29-39.

Luetticke, R. (2019). Transmission of monetary policy with heterogeneity in household portfolios. University College London working paper.

Mavroeidis, S., Plagborg-Møller, M., and Stock, J. H. (2014). Empirical evidence on inflation expectations in the new keynesian phillips curve. Journal of Economic Literature, 52(1):124-88.

McKay, A., Nakamura, E., and Steinsson, J. (2016). The power of forward guidance revisited. American Economic Review, 106(10):3133-58.

McKay, A. and Reis, R. (2016). The role of automatic stabilizers in the us business cycle. Econometrica, 84(1):141-194.

Mian, A. and Sufi, A. (2012). The effects of fiscal stimulus: Evidence from the 2009 cash for clunkers program. The Quarterly journal of economics, 127(3):1107-1142.

Midrigan, V. (2011). Menu costs, multiproduct firms, and aggregate fluctuations. Econometrica, 79(4):1139-1180.

Nakamura, E. and Steinsson, J. (2010). Monetary Non-neutrality in a Multisector Menu Cost Model. The Quarterly Journal of Economics, 125(3):961-1013.

Ogaki, M. and Reinhart, C. M. (1998). Measuring intertemporal substitution: The role of durable goods. Journal of political Economy, 106(5):1078-1098.

Pakoš, M. (2011). Estimating intertemporal and intratemporal substitutions when both income and substitution effects are present: the role of durable goods. Journal of Business 85 Economic Statistics, 29(3):439-454.

Reifschneider, D. and Williams, J. C. (2000). Three lessons for monetary policy in a low-inflation era. Journal of Money, Credit and Banking, pages 936-966.

Romer, C. D. and Romer, D. H. (2004). A new measure of monetary shocks: Derivation and implications. American Economic Review, 94(4):1055-1084.

Sterk, V. and Tenreyro, S. (2018). The transmission of monetary policy through redistributions and durable purchases. Journal of Monetary Economics, 99:124-137.

Tenreyro, S. and Thwaites, G. (2016). Pushing on a string: Us monetary policy is less powerful in recessions. American Economic Journal: Macroeconomics, 8(4):43-74.

Werning, I. (2015). Incomplete markets and aggregate demand. Technical report, National Bureau of Economic Research.

Wieland, J. F. and Yang, M.-J. (2017). Financial dampening. Technical report, National Bureau of Economic Research.

Winberry, T. (2018). Lumpy investment, business cycles, and stimulus policy. Forthcoming in American Economic Review.

Woodford, M. (2003). Interest and Prices. Princeton University Press, Princeton, NJ. 